\title{
ВСПОМОГАТЕЛЬНЫЕ РЕПРОДУКТИВНЫЕ ТЕХНОЛОГИИ: НОВЫЕ ВОЗМОЖНОСТИ
}

\section{ОЛЬГА ИСУПОВА}

\begin{abstract}
В статье содержится попытка оценки возможностей вспомогательных репродуктивных технологий (ВРТ) влиять на рождения, выполненная с учетом последних доступных мировых, европейских и российских статистических данных. ВРТ рассматриваются в историческом и этическом контекстах, от которых во многом зависит распространенность их использования $и$ готовность населения решать с их помощью свои репродуктивные проблемы. Анализ существующей статистики, возможно, неполной и недостаточной, позволяет с осторожностью предположить, что в мировом масштабе многие показатели эффективности ВРТ вышли на некое «плато», рост приостановился, произошла стабилизация. В некоторых странах показатели доступности этих технологий населению также стабилизировались, там, где они приблизились к максимальным, доля ВРТ-детей в рождаемости превышает 4\%. «Старые» репродуктивные технологии - ЭКО, ИКСИ, суррогатное материнство и донорство гамет - уже заняли в области репродуктивных опций свою «нишу», потенциал расширения которой невелик. Это связано, в частности, с борьбой $c$ многоплодием и практикой переноса меньшего числа эмбрионов в одном иикле, которая несколько снижает прочент наступления беременностей, но зато улучшает состояние здоровья появляюшихся детей. Увеличение демографического значения ВРТ может произойти, если: они станут доступнь экономически и географически большему количеству людей; при их использовании женщинами относительно молодого репродуктивного возраста (до 34 или хотя бь до 40 лет) будет снижаться роль предрассудков и религиозных запретов; получат развитие новые технологии, например, позволяющие женщинам старшего возраста с помощью ЭКО иметь генетически своих детей (замораживание яйцеклеток, ткани яичника, донорство ичитоплазмы).
\end{abstract}

Ключевые слова: репродуктивные технологии, биоэтика, рождаемость, демографические возможности ВРТ, репродуктивный выбор.

\section{ВВЕДЕНИЕ}

$\mathrm{BPT}^{1}$, или вспомогательные репродуктивные технологии - это современная область медицины, имеющая определенное демографическое значение, поскольку таким образом на свет появляются довольно большое в мировом масштабе число людей, которые иначе не родились бы.

ОЛЬГА ГЕНРИХОВНА ИСУПОВА (oisupova@hse.ru), НАЦИОНАЛЬНЫЙ ИССЛЕДОВАТЕЛЬСКИЙ УНИВЕРСИТЕТ «ВЫСШАЯ ШКОЛА ЭКОНОМИКИ», РОССИЯ.

СТАТЬЯ ПОДГОТОВЛЕНА ПО РЕЗУЛЬТАТАМ ИССЛЕДОВАТЕЛЬСКОГО ПРОЕКТА «ТЕНДЕНЦИИ ДЕМОГРАФИЧЕСКОГО РАЗВИТИЯ РОССИИ В 2005-2015 ГГ. В КОНТЕКСТЕ ДОЛГОВРЕМЕННЫХ ДЕМОГРАФИЧЕСКИХ ТРЕНДОВ», ВЫПОЛНЕННОГО В РАМКАХ ПРОГРАММЫ ФУНДАМЕНТАЛЬНЫХ ИССЛЕДОВАНИЙ НИУ ВШЭ В 2016 Г.

СТАТЬЯ ПОСТУПИЛА В РЕДАКЦИЮ В НОЯБРЕ 2016 Г.

1 Вспомогательные репродуктивные технологии (ВРТ), основанные на медицинских манипуляциях, позволяющих получить зачатие человека, как правило, вне организма матери. При этом может использоваться как генетический материал будущих социальных родителей, так и доноров (соответственно методы донация спермы и/или донация яйцеклетки); если основной проблемой является отсутствие/несостоятельность матки, вынашивать созданный в пробирке эмбрион генетических родителей может так называемая суррогатная мать. 
Существование этих технологий требует осмысления с разных точек зрения: с точки зрения антропологии (обновление понятия родства: теперь оно может быть не только биологическим и социальным, но и биологическим частично, впервые в истории происходит разделение на части - гестационную и генетическую - материнства ${ }^{2}$, т.е. его деконструкция); биоэтики (возникают новые этические вопросы относительно допустимости выбора определенных характеристик будущих детей, повышенной роли медиков в появлении на свет детей, суррогатного материнства и донорства яйцеклеток как репродуктивной эксплуатации, возможного увеличения процента детей с врожденными дефектами в популяции и т.д.); религии (расширяется пространство репродуктивного выбора, который некоторые представители религиозной мысли осуждают в принципе). Для демографии важно то, что сейчас ВРТ представляют собой наиболее эффективное известное средство преодоления бесплодия, способствуя, таким образом, появлению немалого количества новых людей, которых иначе просто не было бы.

Демографические возможности репродуктивных технологий связаны также и с тем, что расширяют круг потенциальных родителей. К ним могут и в ряде стран начинают прибегать люди гомосексуальной ориентации; женщины, откладывающие материнство на поздний репродуктивный и пострепродуктивный возраст; женщины с различными соматическими заболеваниями: онкологическими, сердечными, диабетом и т.д. Существует также возможность посмертного появления детей у людей, пока это в основном касается мужчин, - это возможно, даже если сперма извлекается из тела в первые несколько часов после смерти. В Израильской армии, например, у всех военных, участвующих в боевых действиях, есть возможность сдать и заморозить сперму, чтобы в случае гибели такого человека родственники могли найти женщину, которая захочет родить ребенка от него из альтруистических или коммерческих соображений.

C точки зрения изучения репродуктивного выбора и репродуктивных намерений ВРТ создают новую область, которая теперь может учитываться при принятии репродуктивных решений в самых разных случаях: при откладывании деторождения женщинами на поздний возраст; при решении о том, что делать с бесплодием в паре, когда оно уже известно; при желании родить ребенка без врожденных заболеваний; в случае возникновения репродуктивных желаний у людей нетрадиционной сексуальной ориентации. Все эти вопросы изучаются исследователями различных направлений в разных регионах мира. В настоящей статье хотелось бы остановиться на анализе последней доступной статистики развития ВРТ в Европе и мире, прежде всего с точки зрения репродуктивного здоровья, а также развития использования тех методов, которые могут быть интересны не только бесплодным, но и представителям других вышеописанных категорий населения.

В этом отношении имеют значение показатели эффективности, доступности и распространенности ВРТ в их динамике, а также биоэтические соображения, влияющие на доступность и использование технологий. Ведь какими бы ни были возможности науки,

\footnotetext{
${ }^{2}$ См. об этом подробнее, например, в [Исупова и др. 2014].
} 
важно, с точки зрения потенциала увеличения рождаемости, готовы ли люди их использовать, какие именно группы людей их используют и как именно.

\section{С ЧЕГО ВСЕ НАЧИНАЛОСЬ И К ЧЕМУ ИДЕТ: КРАТКИЙ ИСТОРИЧЕСКИЙ ОБЗОР ВОЗНИКНОВЕНИЯ И РАЗВИТИЯ РЕПРОДУКТИВНЫХ ТЕХНОЛОГИЙ}

В 1890 г. Уолтер Хип, Кембриджский профессор, сообщил о первом известном ему случае переноса эмбриона у кроликов. Олдос Хаксли, описывая технологию ЭКО 3 в своей повести «О дивный новый мир» (1932 г.), делал это в то же самое время, когда эксперименты биологов в соответствующей области получили дальнейшее развитие: в 1934 г. Грегори Пинкус смешал сперму и яйцеклетки кроликов в стеклянном колпачке от своих часов и в дальнейшем пересадил получившийся эмбрион суррогатной маме-крольчихе. В 1948 г. Мириам Менкен и Джон Рок работали над техникой извлечения яйцеклеток у женщин и извлекли более 800. Но только в 1959 г. Мин Че Чанг, молодой китайский исследователь, получил несомненное свидетельство рождения живого детеныша у кроликов после оплодотворения инвитро (пересадив зародыш от черных кроликов белой крольчихе) [Kamel 2013]. Аналогичные эксперименты проводились и в СССР, и был получен положительный результат в Симферополе в 1948 г. [Петров 1959].

В 1973 г. была получена первая человеческая беременность после оплодотворения инвитро (Карл Вуд и Джон Литон, Мельбурн, Австралия). Но она закончилась смертью эмбриона менее чем через неделю беременности. В 1976 г. у Патрика Степто и Роберта Эдвардса в Великобритании получилась первая внематочная ЭКО-беременность. И, наконец, 25 июля 1978 г. они же добились рождения первого живого ЭКО-ребенка, Луизы Браун. В том же году, 16 октября, в клинике Степто и Эдвардса родилась Кортни Кросс, а 14 января 1979 г. родился первый ЭКО-мальчик, Алистер Макдональд.

Первый австралийский ЭКО-ребенок, Кэндис Рид, родилась в Австралии 23 июня 1980 г., в этом же году открылась первая ЭКО-клиника в США, и появился метод преимплантационной диагностики с помощью биопсии эмбриона (его автором стал Алан Хэндисайд, Великобритания). В 1981 г. родилась Элизабет Джордан Карр, первый американский ЭКО-ребенок, в 1982 г. - первая ЭКО-двойня (в Великобритании), в этом же году появились первые ЭКО-дети во Франции, Швеции, Германии и Австрии. В 1983 г. Алан Траунсон добился рождения первых детей из донорских яйцеклеток у женщин с неработающими или отсутствующими яичниками. В этом же году родилась первая ЭКО-

\footnotetext{
3 ЭКО - Экстракорпоральное оплодотворение, когда яйцеклетка, извлеченная из тела женщины с помощью пункции, помещается в среду со сперматозоидами для оплодотворения и последующего переноса эмбриона (зародыша) в матку. При этом, как и в естественных условиях, одна яйцеклетка встречается с миллионами сперматозоидов, которые «сами решают», кто из них совершит оплодотворение. ИКСИ - русскоязычная калька с английского термина ICSI (introcytoplasmic sperm injection), точнее ИЦИС (интрацитаплазматическая инъекция спермы) - инъекция сперматозоида в яйцеклетку, используемая при наличии мужского фактора бесплодия. Первичным бесплодием называется ситуация, когда зачатие не наступает у женщины фертильного возраста, не бывшей ранее беременной и живущей регулярной половой жизнью с одним и тем же партнером в течение не менее года. О вторичном бесплодии говорят, если при тех же условиях бесплодие наблюдается у женщины, бывшей ранее беременной, независимо от того, чем завершилась беременность (внематочной беременностью, выкидышем, абортом или родами).
} 
тройня, в следующем - «четверня». В 1984 г. появился первый ребенок из размороженного эмбриона (криоперенос) $)^{4}$ в Австралии, а в Калифорнии - первый ребенок, рожденный суррогатной матерью [Kamel 2013]. В этом же году в Австралии возникли первые попытки законодательного регулирования процесса.

В 1985-1986 гг. были получены первые успешные беременности с использованием различных техник извлечения спермы из организма мужчины при невозможности ее получения естественным путем. В 1986 г. родилась первая ЭКО-девочка в России, Елена Донцова (Москва, лаборатория Леонова), а затем и мальчик, Кирилл, в Санкт-Петербурге. В этом же году состоялся первый связанный с технологиями судебный процесс в США (Мелисса Стерн, «бэби М»), поскольку суррогатная мать не захотела отдавать ребенка биородителям (на самом деле она была полной биологической матерью, по договору она вынашивала генетически своего ребенка после инсеминации ${ }^{5}$ и должна была отдать его генетическому отцу ребенка и его жене), положивший начало проблематизации суррогатного материнства и его запрету во многих странах мира.

В 1992 г. было впервые успешно применено ИКСИ ${ }^{6}$, которое позволило становиться биологическими отцами мужчинам с азооспермией (видимым отсутствием здоровых сперматозоидов/вообще любых сперматозоидов в эякуляте), в последнем случае единичные сперматозоиды извлекались из тестикулов и для ИКСИ этого оказалось достаточно (методика разработана Джанпьеро Палермо и Андре Ван Стейртегемом, Бельгия, Брюссель). Все это время развивались разнообразные техники гормональной стимуляции овуляции и извлечения половых клеток у мужчин и женщин все более эффективными и щадящими методами, а также совершенствовались среды для раннего выращивания эмбрионов в лабораторной посуде.

В 1996 г. была создана первая клонированная овечка Долли, и с тех пор работы по превращению обычных клеток организма в половые гаметы не прекращались. В 1997 г. были осуществлены первые опыты по донации цитоплазмы яйцеклетки при сохранении ее ядра за (основной) генетической родительницей. В 1998 г. родился первый ЭКО-ребенок в Африке южнее Сахары - в Нигерии (Ханнату Купчи) [Kamel 2013].

В 1999 г. появились первые успехи в области замораживания яйцеклеток (Лилия Кулешова; до этого успешно замораживались только сперма и оплодотворенные зародыши). Натали Браун, сестра Луизы, 40-й ЭКО-ребенок мира, родившаяся в 1982 г., в 1999 г. родила ребенка самостоятельно после естественного зачатия. В 2000 г. впервые произошла удачная трансплантация ткани яичника. В этом же году родился первый

\footnotetext{
${ }^{4}$ Криоконсервация и криоперенос - перенос ранее полученных при стимуляции и потом замороженных эмбрионов (чтобы не переносить более двух в одном цикле во избежание осложнений, связанных с многоплодием).

${ }^{5}$ Искусственная инсеминация - применяется при не очень тяжелых формах мужского бесплодия, при этом женщина может стимулироваться гормонально; яйцеклетки из ее тела не извлекаются, но сперма вводится в организм женщины искусственно, как правило, с помощью специального катетера.

${ }^{6}$ ИКСИ - инъекция сперматозоида в яйцеклетку; применяется при тяжелых формах мужского бесплодия; основная цель при этом состоит в «помощи» сперматозоиду при его проникновении через оболочку яйцеклетки, т.е. при оплодотворении.
} 
ребенок, зачатый после посмертного извлечения спермы из тела мужчины, а также впервые была оплодотворена яйцеклетка мыши без участия сперматозоидов, что открыло дорогу последующим попыткам однополого размножения.

В 2001 г. были получены первые 6-клеточные человеческие клоны (частной Американской компанией Advanced Cell Technology в целях исследования стволовых клеток).

В 2004 г. Жак Донне сообщил о рождении первого ребенка после успешной имплантации функционирующей собственной ткани яичника, до этого подвергнутой заморозке; это очень важный метод для того, чтобы женщины, заболевшие раком, могли после излечения иметь генетически своих собственных детей. С этого года для таких женщин начали вводиться соответствующие специальные программы. Для них же также возможны программы с дозреванием яйцеклеток в лабораторной посуде и их последующим замораживанием.

В 2008 г. Райо Деви Лохан и Омкари Панвар стали самыми старыми мамами в мире, родив в 70 лет в Индии (от донорских яйцеклеток). В 2009 г. Надя Сулейман, 33-летняя американка иракского происхождения, родила в Калифорнии вторую за всю историю «восьмерню» - 6 мальчиков и 2 девочек. В данном случае это была не гормональная стимуляция, а специально выполненный перенос 12 зародышей одновременно - всех замороженных, оставшихся после ее предшествующих «свежих» циклов ЭКО. Медицинский совет Калифорнии посчитал это «угрожающей жизни практикой», у врача отобрали лицензию [Kamel 2013].

И только в 2010 г. Роберту Эдвардсу была наконец-то присуждена Нобелевская премия в области медицины, а в 2012 г. было отпраздновано рождение пятимиллионного ЭКО-ребенка - хотя, конечно, невозможно определить, кто именно им стал.

К 2014 г., по оценкам, в мире уже жило более 5 млн людей, зачатых с помощью репродуктивных технологий. К настоящему моменту их уже, скорее всего, 6000 000, если мировые темпы рождаемости ВРТ-детей сохранились, как минимум, на прежнем уровне.

\section{ӘТИКА, ЗАКОНОДАТЕЛЬСТВО, СОЦИАЛЬНО-ЭКОНОМИЧЕСКИЕ ВОПРОСЫ}

ВРТ оказались прорывом в области преодоления бесплодия, но одновременно вызовом с точки зрения социальных, этических и законодательных вопросов. В связи с их появлением стали особенно острыми проблемы социальной ответственности медицины.

Первые этические рекомендации в этой области были опубликованы еще в 1986 г. Американским обществом фертильности (American Fertility Society) в США.

В 1980-е годы основной общественной проблемой представлялись безопасность применения гонадотропинов (гормонов, используемых для «программирования» овуляторного цикла при ЭКО), доступность и прозрачность статистических данных о наступлении беременностей, получаемых от клиник, и экономические барьеры, влияющие на доступность ВРТ широким слоям населения. В результате необходимость достоверной информации о процентах наступления беременности от клиник во многих государствах (но не в России: клиники этому противодействуют, считая, что доступность такой информации 
повлияет на рыночную конкурентоспособность отдельных клиник; в нашей стране доступна только агрегированная статистика на национальном уровне, также отдельные, как правило, наиболее успешные, клиники, добровольно раскрывают свои данные) была законодательно закреплена.

Законодательно также стало обязательным сообщать о числе переносимых эмбрионов, а со временем и ограничивать его, когда стало ясно, какие существенные риски для здоровья детей связаны с многоплодными беременностями [Brezina et al. 2012].

Но во многих странах обязательность регистрации происходящего не означает ее регламентацию, меры носят исключительно рекомендательный характер. Например, в США врачи должны сообщать о том, сколько эмбрионов было перенесено, но нет законов, разрешающих или запрещающих переносить более определенного их числа. Доступность информации о проценте наступления беременностей в разных клиниках для пациентов помогает им в выборе более результативной клиники, но создает искушение для клиницистов «отбирать» только наиболее перспективных пациентов, отказывая тем, чей случай более сложен, из опасений, что последние испортят им статистику.

Во многих странах количество переносимых за один раз эмбрионов все-таки регламентируется, так как многоплодие связано, в частности, и с повышенной нагрузкой на системы здравоохранения ([Ledger et al. 2006] рассчитали, что в Великобритании расходы в связи с рождением младенца из одноплодной беременности составляют в среднем £3313, в случае рождения двойни - £9122 и тройни - £32,354). Риск для здоровья не только детей, но и матери возрастает с каждым дополнительным развивающимся плодом.

Согласно официальной медицинской статистике в США, в 2007 г. число эмбрионов, переносимых в одном цикле, было в интервале от 2,2 у женщин моложе 35 лет до 3,1 у женщин старше 40 лет, в среднем по стране. При этом частота многоплодия у женщин моложе 35 лет была около 35\% и только 15\% у женщин старше 40 лет, так как с возрастом плодовитость падает [Brezina et al. 2012]. В Европе выходом стало ограничение числа переносимых эмбрионов до 2 и в некоторых странах даже до (как правило) одного (Швеция). Оставшиеся эмбрионы замораживаются и могут быть перенесены в следующий раз. Кумулятивная эффективность при этом оказывается сопоставимой с той, которая получается при переносе большого числа эмбрионов за один раз.

Но, поскольку в некоторых странах, например, в Италии, слишком много запретов в отношении количества оплодотворяемых и переносимых эмбрионов, это создает мотивацию для пар, подвергающихся лечению, производить его за границей, в странах с менее «запретительным» законодательством, например в Испании. По оценкам, такое репродуктивное лечение за границей может составлять до 10\% всех циклов ЭКО/ИКСИ, производимых в мире ежегодно [Ferraretti, Pennings et al. 2010].

Стоимость ВРТ на одно рождение живого ребенка варьируется между странами и является одной из самых существенных не только экономических, но и этических проблем, так как связана с неравномерностью доступа к этим технологиям и преимуществами для тех, кто более состоятелен. В США средняя стоимость одного цикла составляла в 2008 г. USD 9,266 долларов [Omurtag et al. 2009]. При этом стоимость в среднем всех циклов пары, 
понадобившихся для рождения одного живого ребенка, в США, Канаде и Великобритании варьировалась в пределах примерно USD 33,000-41,000, в то время как она была гораздо ниже (USD 24,000-25,000) в Скандинавии, Японии и Австралии.

Общие расходы на лечение методами ВРТ в составе всех расходов на здравоохранение в 2003 г. были 0,06\% в США, 0,09\% в Японии и 0,25\% в Австралии [Chambers et al. 2009]. Но, согласно некоторым расчетам, появление новых членов общества, которые в дальнейшем будут работать, приносит социальную выгоду, превышающую эти расходы, особенно в обществах с низкой рождаемостью и стареющим населением [Garcia 1998].

В США не существует возмещения расходов на ЭКО и другие технологии на федеральном уровне, но есть программы в отдельных штатах [Chambers et al. 2009]. Во многих европейских странах и в Израиле частично или полностью возмещаются расходы на ВРТ через государственное медицинское страхование, но часто это связано с очередями и длительным ожиданием, что заставляет людей проходить лечение в частных клиниках или других странах [Chambers et al. 2009]. Например, в Великобритании в середине 2000-х годов только примерно 25\% ЭКО финансировалось через Национальную систему здравоохранения [Ledger et al. 2006].

Очень быстро в последние годы развивается преимплантационная диагностика. Противоречивым с этической точки зрения в этой области является выбор пола ребенка. В большинстве развитых стран он возможен в настоящее время только в случае наличия отягощенной связанной с полом наследственности, в Таиланде он разрешен в любом случае, что является одной из причин популярности репродуктивного лечения иностранцев в этом государстве [Sharp et al. 2010; Ehrich et al. 2007]. Выбор пола просто по желанию родителей может негативно сказаться на соотношении полов в отдельных странах. Высказывается также обеспокоенность тем, что скоро действительно можно будет выбирать ребенка по цвету глаз и по другим «легкомысленным» или, наоборот, серьезным генетическим основаниям, что уже означает вмешиваться в человеческую природу «слишком сильно». В биоэтике это (возможность конструирования «улучшенной» породы людей) обычно называют позитивной евгеникой, которая достаточно проблематична с этической точки зрения, хотя, возможно, в меньшей степени, чем негативная (уничтожение людей/имплантировавшихся эмбрионов с нежелательными генетическими признаками). В будущем можно будет и менять генную структуру уже существующего эмбриона. Если все это будет происходить, то необходимо всесторонне осмыслить социальную ответственность медицины во всех этих процессах.

Есть доказательства того, что женская плодовитость постепенно уменьшается с возрастом в поздние репродуктивные годы [Van Rooij et al. 2003; Spandorfer et al. 2007]. Соответственно проводилось много исследований, направленных на сохранение плодовитости до старшего возраста. Кроме того, сохранение плодовитости важно в случаях, когда люди заболевают раком, поскольку сейчас довольно велики шансы на излечение, но химиотерапия негативно влияет на половые клетки. Техника, позволяющая замораживать и размораживать яйцеклетки и ткань яичников, стала развиваться относительно недавно, но в самые последние годы в развитых странах стала практически рутинной практикой. 
Многие авторы убеждены, что до начала лечения от рака женщинам должны предлагаться замораживание яйцеклеток или ткани яичника с тем, чтобы впоследствии их можно было пересадить обратно и подвергнуть стимуляции с целью наступления беременности [Rao et al. 2004; Meirow 2008].

Возможность заморозить свои половые клетки с целью забеременеть в нужное время жизни по решению самой женщины имеет такое же революционное значение, как в свое время изобретение гормональной контрацепции, позволившей избегать беременности в тот момент, когда она не нужна. Но технология замораживания яйцеклеток в настоящее время доступна только тем, кто имеет достаточные финансовые средства, т.е. в этой области пока много проблем в отношении равномерности и справедливости доступа к процедуре.

Донация гамет (яйцеклеток и сперматозоидов) давно стала рутинной технологией в области репродуктивных технологий. Использование донорской спермы и инсеминация впервые упоминаются уже в 1800-е годы. В середине 1980-х годов начала применяться также и донация ооцитов. Связанные с этим этические проблемы основаны на том, что донация яйцеклеток подразумевает, что женщины-доноры подвергают риску свое здоровье, о чем они должны быть осведомлены [Murphy 2009; Ethics Committee... 2009; Levens, DeCherney 2008]. Доноры должны отдавать свои клетки добровольно, без принуждения или злонамеренного влияния. Иногда высказываются опасения, что, поскольку за донацию выплачиваются деньги, это может приводить к биологической эксплуатации, причем женщины могут действовать против своих интересов, не отдавая себе отчета в медицинских рисках, связанных с процедурой. С этим связана концепция коммодификации, т.е. приравнивания биологических частей тела или функций к предмету купли-продажи, что некоторыми считается изначально аморальным в своей основе. В связи с этим во многих странах было принято решение запретить коммерческую донацию ооцитов, законной осталась только добровольная, «благотворительная» [Levine 2011].

Большое этическое значение имеет также проблема анонимности доноров [Sauer 2009]. Для людей важна возможность знать свои генетические «корни», это может быть центром их идентичности. Доноры спермы и яйцеклеток могут выбрать как анонимность, так и не анонимность, но большинство выбирает анонимность. Однако соображения относительно прав рожденных таким образом детей обусловили принятие законов, согласно которым эти дети имеют право получить информацию о своем происхождении, и никто не должен им в этом препятствовать [Jadva et al. 2011; Riggs, Russell 2011]. Это связано, в том числе, и с правом людей на знание о своей наследственности в отношении возможной генетической предрасположенности к заболеваниям.

В результате циклов ЭКО часто появляется некоторое число «лишних» эмбрионов генетической пары, поскольку беременность уже наступила, и супруги не планируют больше детей.

Такие эмбрионы хранятся в замороженном виде, в некоторых странах неопределенно долго, и там их очень много (например, в Соединенных Штатах Америки, по оценкам, в 2010 г. было около 400000 замороженных эмбрионов [Paul et al. 2010]). 
Есть четыре возможных пути решения «судьбы» этих эмбрионов: 1) размораживание и уничтожение; 2) передача для исследований; 3) хранение неопределенное время; 4) донация другим людям в целях возможного рождения ими детей.

Существуют убежденные сторонники и противники каждой из четырех стратегий. В разных странах существуют также многочисленные законы, регламентирующие криопрезервацию эмбрионов и их дальнейшую участь. В частности, особенно эмоционально протекают дебаты относительно использования эмбрионов для исследований, поскольку это связано с работами со стволовыми клетками.

Суррогатное материнство с собственной яйцеклеткой женщины, а также и с ооцитом другой женщины также этически очень нагружено. Есть гораздо больше стран, где разрешено второе, в то время как первое доступно в очень небольшом числе стран (например, в США [James et al. 2010; Hanna 2010]). Суррогатные матери, как и доноры яйцеклеток, подвержены значительным медицинским и эмоциональным рискам, связанным с вынашиванием беременности и родами, поэтому нуждаются в консультировании и понастоящему информированном согласии. Есть авторы, которые, с другой стороны, обвиняют этих женщин в «продаже детей». Страны различаются в отношении того, кто имеет преимущественные права на ребенка после его рождения, и в ряде государств, в том числе и в России, преимущество оставлено за суррогатной матерью, даже и не связанной с ребенком генетически. Финансовые вопросы в этой области также вызывают опасения относительно возможной эксплуатации женщин, действующих не в своих лучших интересах. Однако в связи со всеми этими финансовыми, моральными и легальными ограничениями развился международный рынок суррогатного материнства [Osberg 2006; Damelio, Sorensen 2008], существующий именно потому, что позиции разных государств в этой области различаются.

Имеется общий консенсус относительно того, что репродуктивные технологии связаны с крайне небольшим, но измеримым увеличенным риском появления различных генетических отклонений по сравнению с населением в целом [Fortunato, Tosti 2011]. Однако это превышение невелико и не становится причиной для отказа от применения ВРТ как для отдельных людей, так и в мировом масштабе.

\section{ИСПОЛЬЗОВАНИЕ ВРТ В ЕВРОПЕ: СТАБИЛИЗАЦИЯ ИЛИ РОСТ?}

15-й отчет Европейской ассоциации мониторинга ЭКО (ЕIM) содержит самые последние доступные данные по Европе, они за 2011 г. До этого в Европе выходили 14 отчетов, мониторинг репродуктивных технологий в этом регионе по рекомендации ВОЗ происходит, начиная с 1997 г.

Можно отметить, что, по сравнению с более ранними годами, произошли некоторые изменения в статистических трендах, связанных с использованием репродуктивных технологий населением:

- перестало существенно расти число стран, собирающих соответствующую статистику; 
- общее количество лечебных циклов ${ }^{7}$ ВРТ растет;

- процент наступления беременностей падает, поскольку падает количество переносов более чем с тремя эмбрионами и соответственно - процент многоплодия.

Данные, собранные Национальными регистрами в 338 странах, охватывают 1064 клиники. В 2011 г. в Европе было произведено 609973 цикла ВРТ, из них 138592 ЭКО, 298 918 ИКСИ, 129693 криопереносов, 30198 циклов с донорскими яйцеклетками, 511 циклов с дозреванием яйцеклеток в «пробирке», 6824 цикла с ПГД 9 и 5237 циклов переноса эмбрионов, полученных из ранее замороженных яйцеклеток. Кроме того, было произведено 174390 циклов инсеминации с использованием спермы мужа и 41151 - с использованием донорской спермы.

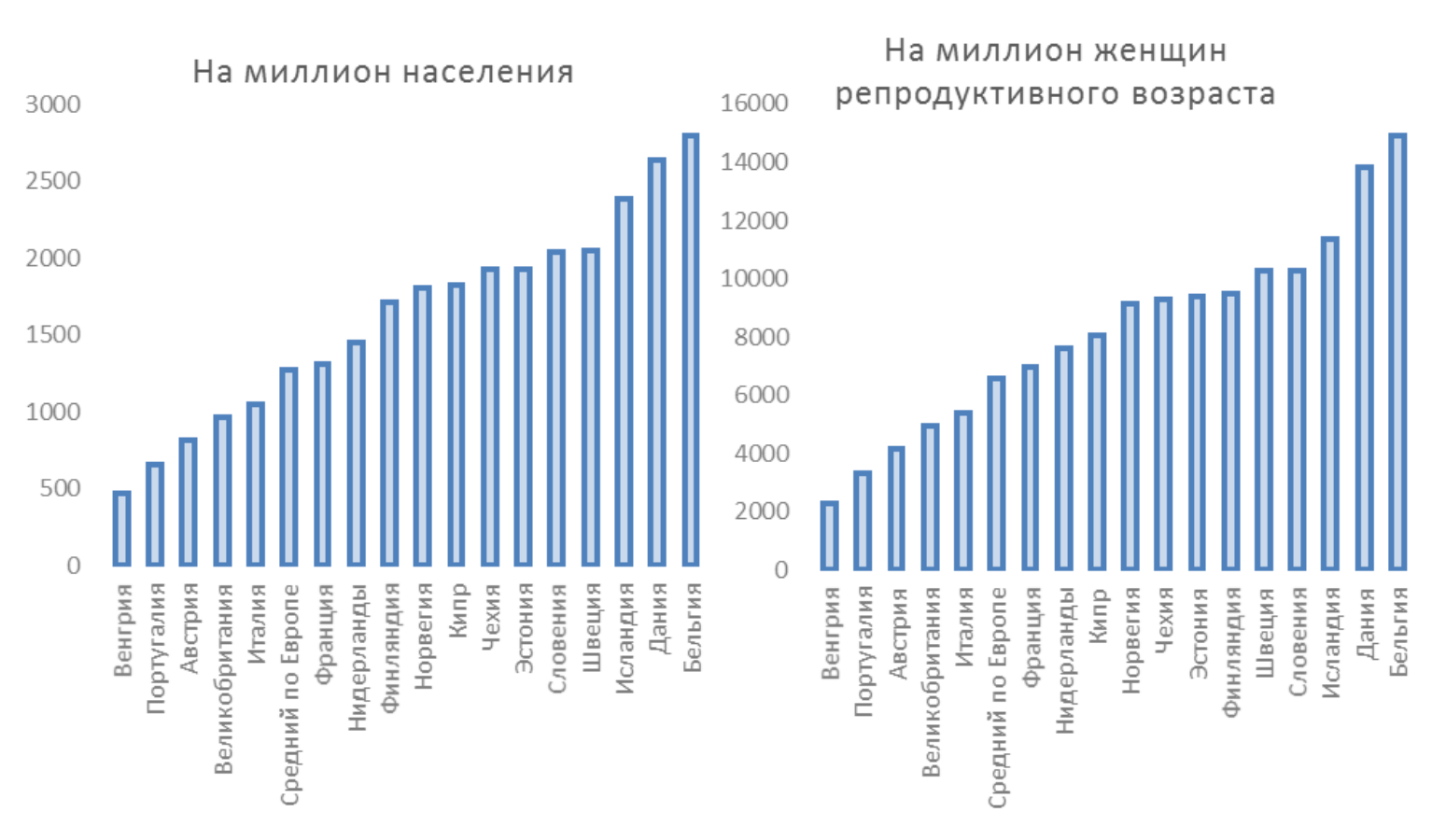

Рисунок 1. Доступность репродуктивных технологий в Европе в 2011 г., количество циклов на 1 млн населения и на 1 млн женщин репродуктивного возраста в отдельных странах

Источник: [Kupka et al. 2016].

7 Лечебный цикл ЭКО - период времени, в течение которого (как правило) происходит гормональная стимуляция созревания яйцеклеток (если они после этого не извлекаются из тела матери и происходит зачатие естественным путем, то это называется просто индукция овуляции), затем с помощью пункции из организма женщины забираются зрелые яйцеклетки (ооциты), соединяются со сперматозоидами, зреют от 2 до 6 дней в чашке Петри и помещаются в матку. После этого назначается «поддержка» другими гормонами, и через 1114 дней делается анализ крови «на беременность».

${ }^{8}$ Источник всех статистических показателей в данном разделе - отчет ESHRE за 2011 г. [Kupka et. al 2016].

9 ПГД - преимплантационная генетическая диагностика, методика, позволяющая определить очень многие генетические аномалии у эмбриона до его переноса в полость матки и соответственно избежать как аборта, так и рождения заведомо больного ребенка, просто отказавшись от переноса эмбриона с аномалиями. 
Можно видеть, что циклов с привлечением генетического материала третьих лиц попрежнему меньше, чем с использованием собственной генетики пары, желающей иметь детей. Средние цифры по странам таковы, что на 17 европейских стран, где все клиники участвовали в отчете, было произведено 361972 циклов на население в 285 млн жителей, т.е. в среднем 1269 циклов на 1 млн жителей (рисунок 1).

Процент наступления беременности при ЭКО на одну пункцию составил в среднем $29,1 \%$, на один перенос эмбрионов - 33,2\%, для ИКСИ - 27,9 и 31,8 соответственно, при крио-процент наступления беременности увеличился и составил $21,3 \%$. При использовании донорских яйцеклеток этот процент был традиционно выше и составил 45,8\% для свежих клеток и 33,6\% для размороженных эмбрионов (размороженные эмбрионы теряют часть своего «жизненного потенциала»).

При инсеминации беременность наступила в 8,3\% случаев при использовании спермы мужа и в 12,2\% случаев - спермы донора, что также достаточно традиционно и естественно, так как фертильность мужей в бесплодных парах, в среднем, несколько ниже, чем таковая у доноров, а инсеминация, что давно известно, менее эффективна, чем различные варианты экстракорпорального оплодотворения.

11819 циклов ВРТ в целом происходили со спермой мужа, которую извлекали хирургическим путем. Для этого также используются различные варианты пункции сперматозоидов или даже клеток, из которых в норме позже формируются сперматозоиды (сперматиды), из яичек или других частей репродуктивного аппарата мужчины в случаях, когда его бесплодие обусловлено либо обструктивными причинами (сперматозоиды образуются, но не могут попасть в эякулят из-за существования в организме тех или иных преград), либо более сложными ситуациями, в которых сперматозоиды даже не могут нормально сформироваться или их очень мало и они не имеют подвижности.

В циклах ЭКО и ИКСИ 1 эмбрион подсаживался в 27,5 \% случаев, 2 - в 56,7\%, 3 - в $14,5 \%, 4+-$ в $1,3 \%$ случаев. В результате были рождены $80,8 \%$ детей в беременности одним плодом, $18,6 \%$ родов составили двойни и $0,6 \%$ - тройни. В криоциклах $12,8 \%$ всех рождений составили двойни и $0,4 \%$ - тройни. При инсеминации спермой мужа двойни появились в 9,7\% случаев, а тройни - в 0,6\%; спермой донора - в 7,3 и $0,3 \%$ случаев соответственно.

Процент ВРТ-детей в общей рождаемости достиг в 2011 г. 5,8\% в Дании. Для сравнения, в Италии, где на уровне законодательства и практики все еще существует ряд ограничений на использование некоторых видов репродуктивных технологий, но при этом медицина достаточно развита, он составлял только 1,7\% (рисунок 2).

Всего в 17 европейских странах, представивших полный отчет в 2011 г., родилось 134106 ВРТ-детей.

Больше всего женщин в возрасте 40 лет и более среди пациенток было в Греции, Швейцарии и Италии, а на Украине, в Белоруссии и Черногории было больше всего пациенток моложе 35 лет. Можно отметить, что в относительно молодом возрасте к ЭКО прибегают в более традиционных европейских странах, где ценность деторождения в жизни каждой женщины пока еще мало кем ставится под сомнение, а также существуют 
представления относительно нежелательности его откладывания на слишком поздние сроки. Наиболее поздно к ЭКО обращаются в странах с так называемыми посттрадиционалистскими ценностями, где материнство откладывается надолго, а женщины либо верят в свою фертильность вплоть до самых поздних репродуктивных лет, либо существуют ограничения на использование донорских яйцеклеток.

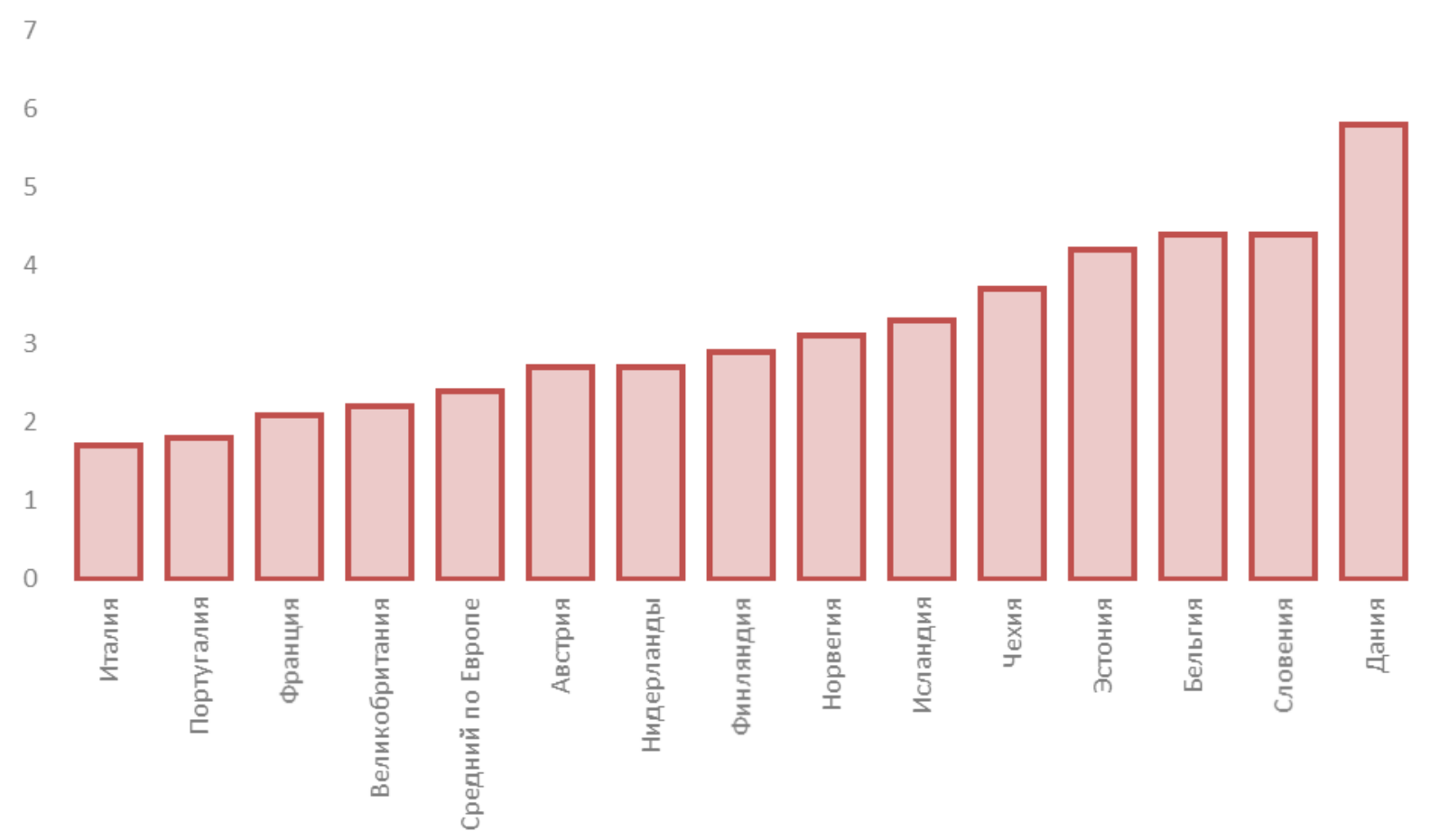

\section{Рисунок 2. Доля ВРТ-детей от общего числа рожденных в европейских странах в 2011 г., \%}

Источник: [Kupka et al. 2016].

Для женщин старше 40 лет, делавших ИКСИ со своими собственными яйцеклетками, процент дошедших до рождения живого ребенка составил от 5,0\% в Чехии до 14,9\% в Казахстане. Собственно говоря, уже давно понятно, что само по себе увеличение среднего возраста матери при рождении может вести к повышению частоты использования ЭКО населением, но не обязательно - к увеличению числа рождений ВРТ-детей и процентной доли ЭКО-детей в общей рождаемости, особенно если учесть незначительную долю использования донорских яйцеклеток в Европе, а также некоторое (возможное, насколько позволяют судить статистические данные) начавшееся падение частоты наступления беременности в донорских протоколах. Ведь вполне возможно, что резервы «здоровья» донорских клеток также могут быть ограничены, и со временем их использование будет давать все меньшую эффективность, поскольку не вполне изучены причины, обусловливающие большую фертильность яйцеклеток одних женщин по сравнению с другими (за исключением молодого репродуктивного возраста).

Что же касается использования собственных замороженных молодых яйцеклеток в старшем репродуктивном и пострепродуктивном возрасте, то тут резервы есть, но пока беременностей от такой технологии немного в общей массе: надежно сохранять 
замороженные яйцеклетки и размораживать их так, что их жизнеспособность сохраняется, научились относительно недавно.

Различия между странами Европы по числу переносимых эмбрионов в 2011 г. зависели прежде всего от степени развития в стране репродуктивных технологий и медицины в целом (а также от распространенности программ финансирования ЭКО не за счет собственных средств пациентов, а за счет государства или страховых компаний).

Чаще всего только один эмбрион переносился в таких странах, как Бельгия (50,4\% всех переносов в этой стране), Финляндия (67,55\%) и Швеция (73,3\%). Более 2 эмбрионов в Швеции и Исландии не переносили ни в одном случае (в Финляндии $0,1 \%$ случаев), в то время как в Болгарии, Греции, Литве, Молдавии, Черногории и Сербии - 3 и более эмбрионов подсаживались в матку в свыше чем 40\% проведенных циклов лечения. Это иллюстрирует противоречие, существующее в этой области, между стремлением к максимальной эффективности каждого цикла и стремлением предотвратить нежелательные последствия многоплодия. 4 и более эмбрионов не переносились в 15 европейских странах, в 9 странах это произошло несколько более чем в 2\% случаев, в Румынии - в 10,4\% случаев.

При этом 88\% ВРТ-детей из одноплодной беременности, зачатых в Европе в 2011 г., родились на нормальном сроке 37 и более недель беременности, но только 46,1\% двоен и $8,6 \%$ троен родились на этом сроке. Известно, что огромная доля проблем со здоровьем при рождении у ВРТ-детей (которые возникают на статистическом уровне несколько чаще, чем у «естественно» зачатых детей) связана, прежде всего, с ранним появлением на свет, которое чаще всего вызывается именно многоплодием. Поэтому с последним борются наиболее развитые страны даже в ущерб повышению эффективности каждого отдельного цикла ВРТ.

В 9 странах происходило «доращивание» яйцеклеток в «пробирке». Всего в Европе в 2011 г. таких циклов было 511, затем произошло 437 переноса, 127 беременностей и 87 родов. По этой процедуре в лидеры вышла Россия - здесь произошло 55\% таких лечебных циклов и 75\% родов после них. Возможность такой процедуры может быть очень важной для тех женщин, чье здоровье особенно сильно страдает от чрезмерной гормональной стимуляции, поскольку в данном случае значительной части гормонального воздействия подвергается не весь организм женщины, а уже извлеченные из него яйцеклетки.

Перенос эмбрионов, полученных из ранее замороженных яйцеклеток, в 2011 г. осуществлялся в 10 европейских странах, число случаев применения этого метода выросло (5 237 в 2011 г. и только 4859 в 2010 г.), при этом в 4368 случаях переноса эмбриона в 2011 г. было получено 1415 беременностей и 853 рождения. 93\% таких случаев произошло в Италии и Испании, где проблема с использованием/невозможностью использования донорских яйцеклеток при росте среднего возраста материнства стоит наиболее остро.

22 европейские страны в 2011 г. отчитались о проведении 174390 циклов внутриматочной инсеминации спермой мужа (чаще всего это происходило во Франции и Италии). В среднем в 8,3\% случаев такое воздействие закончилось родами. Инсеминация донорской спермой происходила в основном в Дании, Испании и Бельгии, количество 
случаев ее использования растет, в случае этой процедуры роды были несколько чаще $12,2 \%$ случаев.

Кумулятивный процент (рисунок 7) рождений на одну стимуляцию с последующей пункцией (учитывающий суммарно все свежие и все криопротоколы на одну пункцию) показывает финальную эффективность каждого протокола при использовании также и криозамораживания (на самом деле этот показатель считается иначе, суммарное число рождений после крио- и «свежих» протоколов в стране делится на количество пункций). В среднем по Европе процент рождений на одну пункцию при учете только «свежих» протоколов составил $19,7 \%$, а кумулятивный - 24,0\%, но в некоторых странах получаемый при таком расчете прирост был существенно больше (Финляндия - +13,4\%, Швейцария $+10,2 \%)$, что зависит как от техник замораживания/размораживания, так и от преобладания практики переноса только одного эмбриона - при этом более вероятно, что на замораживание остаются эмбрионы более высокого «качества» / жизнестойкости. Качество сбора статистических данных значительно варьируется от страны к стране, что может оказывать существенное влияние на результат. Однако у нас нет других данных, и мы неизбежно вынуждены использовать средние показатели, основанные на имеющейся статистике.

Только 7 стран отчитались о репродуктивном лечении у них граждан других государств: Белоруссия, Исландия, Черногория, Польша, Словения, Испания и Швейцария. Согласно отчетам, всего циклов такого лечения было 3 507, из них 60,0\% - с собственными половыми клетками пары, 17,6\% были связаны с донацией ооцитов и 21,8\% - спермы. Информация по странам происхождения пациентов, а также по причинам выбора ими лечения в другой стране была неполной и недостаточно достоверной.

В 2011 г. в США было проведено 101213 цикла ВРТ, в Австралии и Новой Зеландии - 40696 (источники: специализированные статистические организации соответствующих стран). В обоих регионах произошло незначительное падение количества циклов по сравнению с предыдущим годом.

Странами-лидерами по доступности лечения, способными предоставить более 10000 циклов на 1 млн женщин репродуктивного возраста, в 2011 г. были Бельгия 930), Дания (13 824) и Исландия (11 366), а также Словения и Швеция (рисунок 1). Процент новорожденных, зачатых с помощью ВРТ, в Европе варьировался от 0,2\% в Румынии до $5,8 \%$ в Дании (рисунок 2).

\section{ВРТ В МИРЕ}

В мире в целом ${ }^{10}$ использование и эффективность репродуктивных технологий вышли на некое плато, хотя есть заметные межстрановые различия. За каждый исследуемый год из числа трех последних, по которым есть данные (2008, 2009 и 2010), отчеты присылали от

\footnotetext{
${ }^{10}$ Источник статистических показателей этого раздела [Dyer et al. 2016], также использованы более поздние данные по США [Center for disease... 2014], Австралии и Новой Зеландии [Macaldowee et al. 2013].
} 
58 до 61 страны. За эти три года в мире было выполнено более 4461309 циклов ВРТлечения, в результате, по оценкам, родилось в общей сложности 1144858 детей (рисунок 5).

Количество пункций в мире выросло на 6,4\% между 2008 и 2010 гг. Количество случаев переноса единичного эмбриона, что помогает предотвращать многоплодие и его негативные последствия, возросло на 27,6\%. На глобальном уровне доступность ВРТ выросла незначительно - с 436 циклов на 1 млн населения в 2008 г. до 474 в 2010 г. по миру в среднем, но межстрановые различия велики (минимум 8 и максимум 4775 циклов на 1 млн населения; рисунок 6).

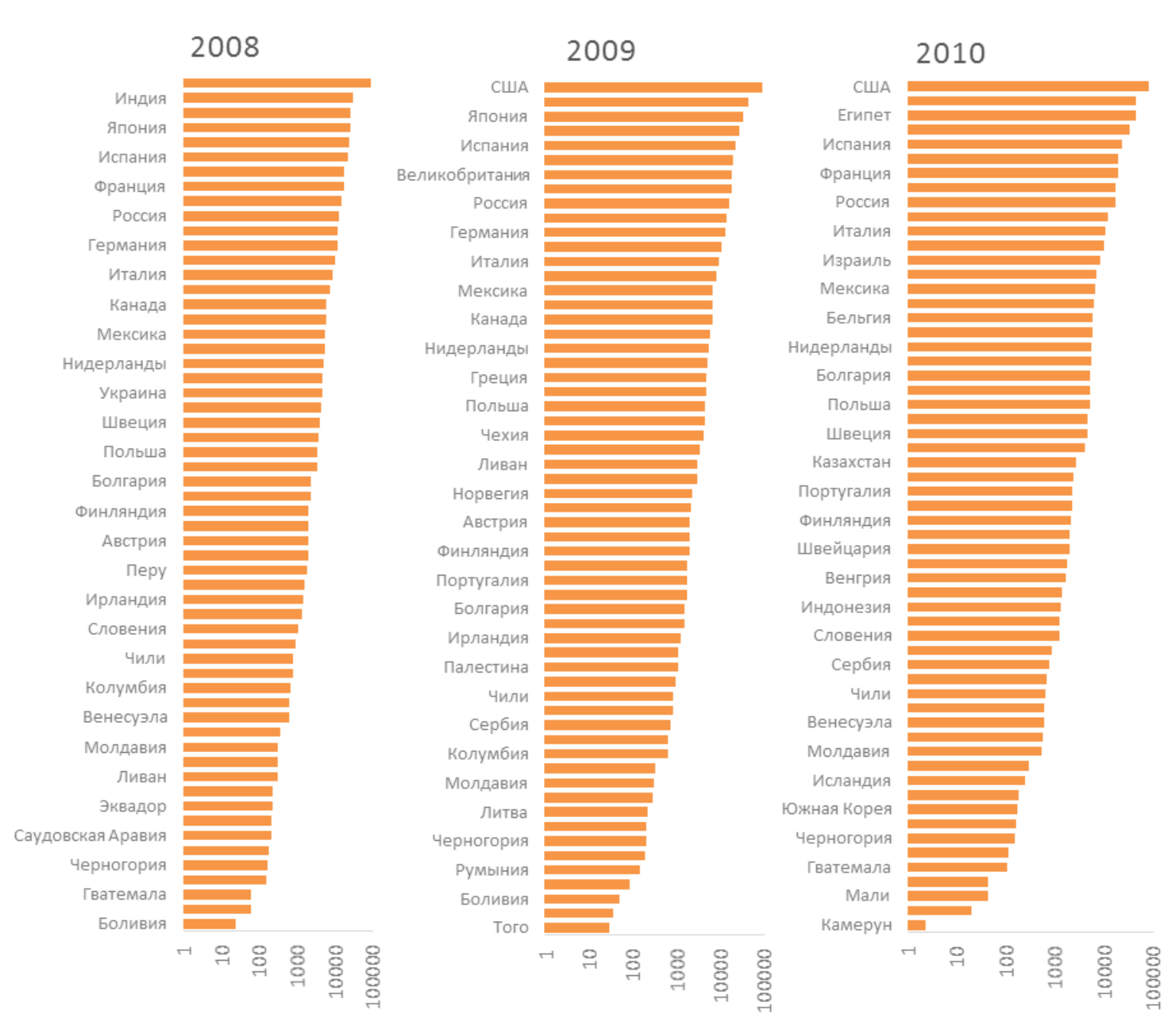

Рисунок 3. Число детей, родившихся в результате ВРТ в мире, 2008, 2009, 2010

Источник: [Dyer et al. 2016].

Эффективность ЭКО/ИКСИ, рассчитанная для их общего количества по миру, для «свежих» протоколов составляла 19,8\% на цикл лечения в 2008 г., 19,7\% в 2009 г. и 20,0\% в 2010 г., для криопереносов эффективность была 18,8, 19,7 и 20,7\% по годам соответственно. Можно отметить некоторое увеличение эффективности для крио-, в то время как в «свежих» протоколах она оставалась примерно на одном и том же уровне. 
Двойни рождались в «свежих» не донорских циклах в 21,8, 20,5 и 20,4\% случаев в исследуемые годы, тройни - в 1,3, 1,0 и 1,1\% случаев, т.е. доля многоплодия неуклонно, хотя и не быстро и не очень значительно, особенно по сравнению с более заметным трендом в Европейском регионе, в мире падает. Уровень перинатальной смертности для свежих ЭКО- и ИКСИ-циклов составил 22,8\%о в 2008 г., 19,2\%о в 2009 г. и 21,0\%о в 2010 г., для криодетей он был меньше - соответственно 15,1, 12,8 и 14,6\%. Это может быть отчасти связано со значительно улучшившимися в этот период техниками криопрезервации эмбрионов и соответственно с их повысившейся в целом жизнестойкостью. Пропорция женщин старше 40 лет по миру выросла с 20,8 до 23,2\% с 2008 по 2010 г.

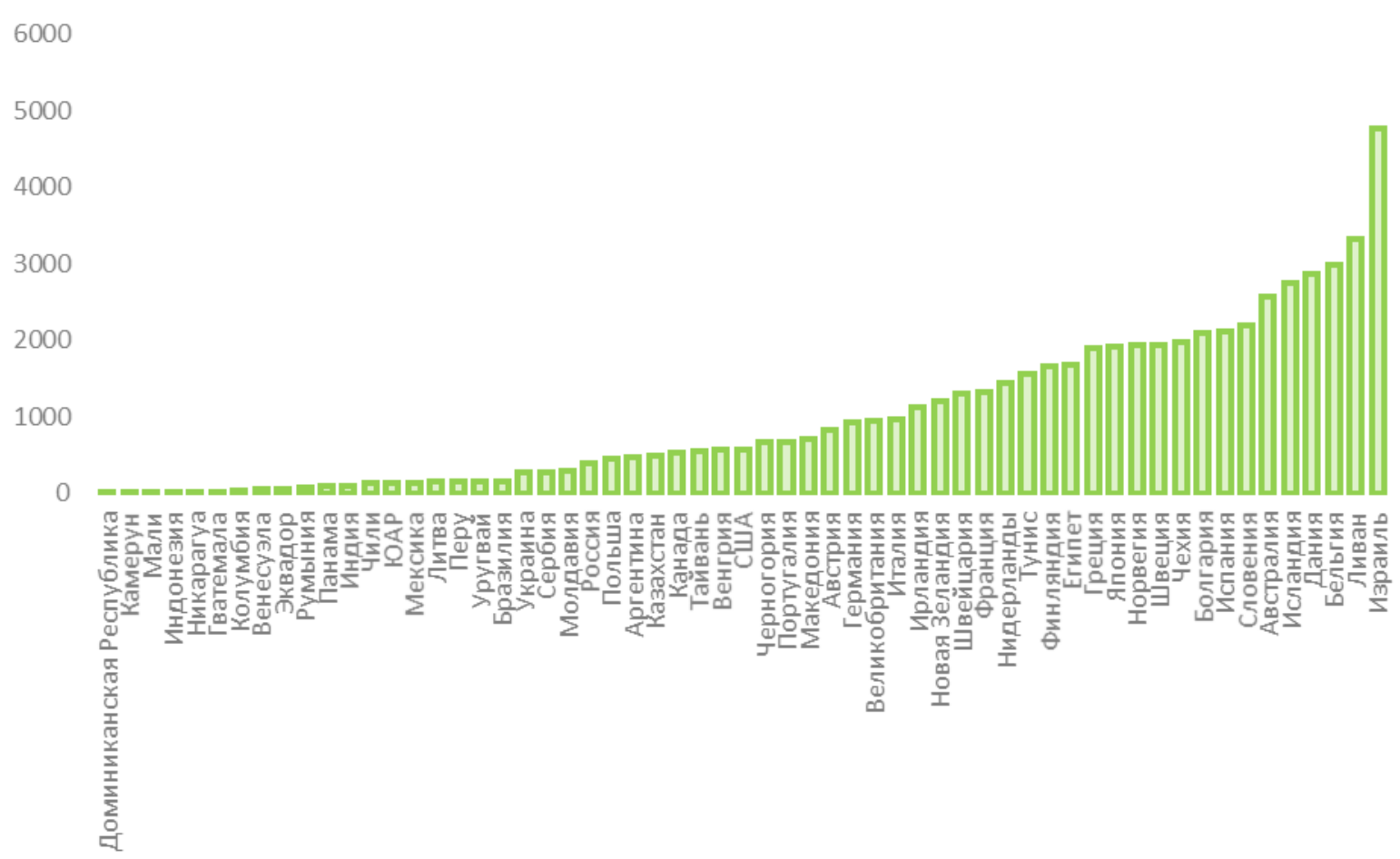

Рисунок 4. Количество циклов ВРТ на 1 млн населения в странах мира, 2010

Источник: [Dyer et al. 2016].

В эти три года клиники, где происходило менее 100 лечебных циклов в год, в основном существовали в Африке южнее Сахары и в Азии, в то время как в Израиле и Австралии/Новой Зеландии более 40\% клиник выполняли более 1000 циклов в год. В 2008 г. было выполнено 1364943 цикла ВРТ, 1452910 в 2009 г. и 1643456 в 2010 г. С точки зрения доступности ВРТ населению (рисунок 6) минимальным было число циклов на 1 млн населения в Доминиканской Республике (8 в 2010 г.), а максимальным - в Израиле (4 775, также в 2010 г.). В этом же году, если говорить о больших мировых регионах, доступность была наиболее высокой в Австралии/Новой Зеландии (2 337 циклов на 1 млн населения) и наиболее низкой в Латинской Америке (152), а также Африке южнее Сахары (87).

Весьма интенсивно работали клиники Японии: там было выполнено 18,2\% всех пункций этого трехлетия, в США - 10,7\%, во Франции - 7,2\%. Перенос размороженных эмбрионов чаще всего происходил в Японии, США и Австралии. Неравенство в отношении доступности ВРТ является одной из сторон неравенства в области доступности репродуктивной медицины и услуг в области репродуктивного здоровья, в результате 
здоровье и благосостояние женщин и их семей поддерживаются недостаточно, что противоречит базовому праву человека на создание семьи и рождение детей [Inhorn 2009; Zegers-Hochschild et al. 2013].

Процент наступления беременности и родов для всех не донорских циклов ЭКО/ИКСИ в течение этого трехлетия был довольно стабильным с незначительными флуктуациями: 26,1\% (беременности на одну пункцию) и 19,1\% (роды на одну пункцию) в 2008 г.; соответственно 26,1 и 18,9\% в 2009 г.; 25,4 и 19,1\% в 2010 г. В циклах ИКСИ беременности наступали чаще, но постепенно эффективность немного падала, а процент родов был примерно таким же, как при ЭКО/ИКСИ в целом, но постепенно немного увеличивался: 28,7 и 18,9\% в 2008 г.; 27,7 и 19,9\% в 2009 г.; 26,8 и 20,0\% в 2010 г. Среднее общемировое число переносимых за один раз эмбрионов в «свежих» не донорских циклах ЭКО и ИКСИ постепенно уменьшалось, но несущественно: 2,1 в 2008 г., 2,0 в 2009 г. и 1,9 в 2010 г. В криопротоколах число переносимых эмбрионов также постепенно уменьшалось с 1,72 (2008 г.) до 1,65 (2009 г.) и затем до 1,60 (2010 г.). Кумулятивный процент родов на одну пункцию вырос с 25,7\% в 2008 г. до 26,1\% в 2009 г. и до 27,1\% в 2010 г., но региональные вариации были довольно велики: от 17,8\% в Азии в 2008 г. до 44,5\% в Северной Америке в 2010 г.

Потеря беременности на раннем сроке в мировом масштабе при ЭКО/ИКСИ оставалась примерно на одном и том же уровне $(21,8,21,1$ и 20,2\% в изучаемые годы в календарном порядке), но региональные вариации были велики и здесь - от 18,3\% в Латинской Америке в 2008 г. до 38\% в Азии в 2008 г.

За эти три года по отчету клиник, участвовавших в мировом регистре ВРТ, родилось 803792 ребенка. Цифра в 1144858 ребенка получается, если добавить к этому оценки работы клиник, в регистре не участвовавших. Пропорция женщин старше 40 лет, проходящих лечение в не донорских циклах ЭКО/ИКСИ, продолжала увеличиваться с $20,8 \%$ в 2008 г. до 23,2\% в 2010 г. (в 2006 г. было 15,5\%). Этот прирост происходил в каждом регионе. При этом процент наступления беременности и родов в этой возрастной группе практически не увеличивался: 11,6 и 6,5\% в 2008 г., 13,5 и 7,5\% в 2009 г., 11,7 и 6,6\% в 2010 г. Если женщины этого возраста использовали свои собственные ранее созданные замороженные эмбрионы, процент наступления беременности и родов был заметно выше: около $20 \%$ для беременностей и чуть выше $11 \%$ для родов на протяжении всех трех лет.

Наиболее часто один эмбрион в одном цикле переносился в 2010 г. в Швеции $(73,3 \%)$, Японии (70,0\%) и Финляндии $(67,5 \%)$. На региональном уровне чаще всего только один эмбрион переносился в Австралии/Новой Зеландии $(63,5,64,9,64,4 \%$ по годам в календарном порядке), затем в Азии (43,2, 46,6, 51,2\%). Три эмбриона чаще всего переносили на Ближнем Востоке $(59,8,47,3,48,8 \%)$, затем в Латинской Америке $(36,4,34,3$, 34,6\%). К 2010 г. перенос 4+ эмбрионов был наиболее высоким в Северной Америке и в Африке южнее Сахары (10\%), в остальных регионах он был ниже. 

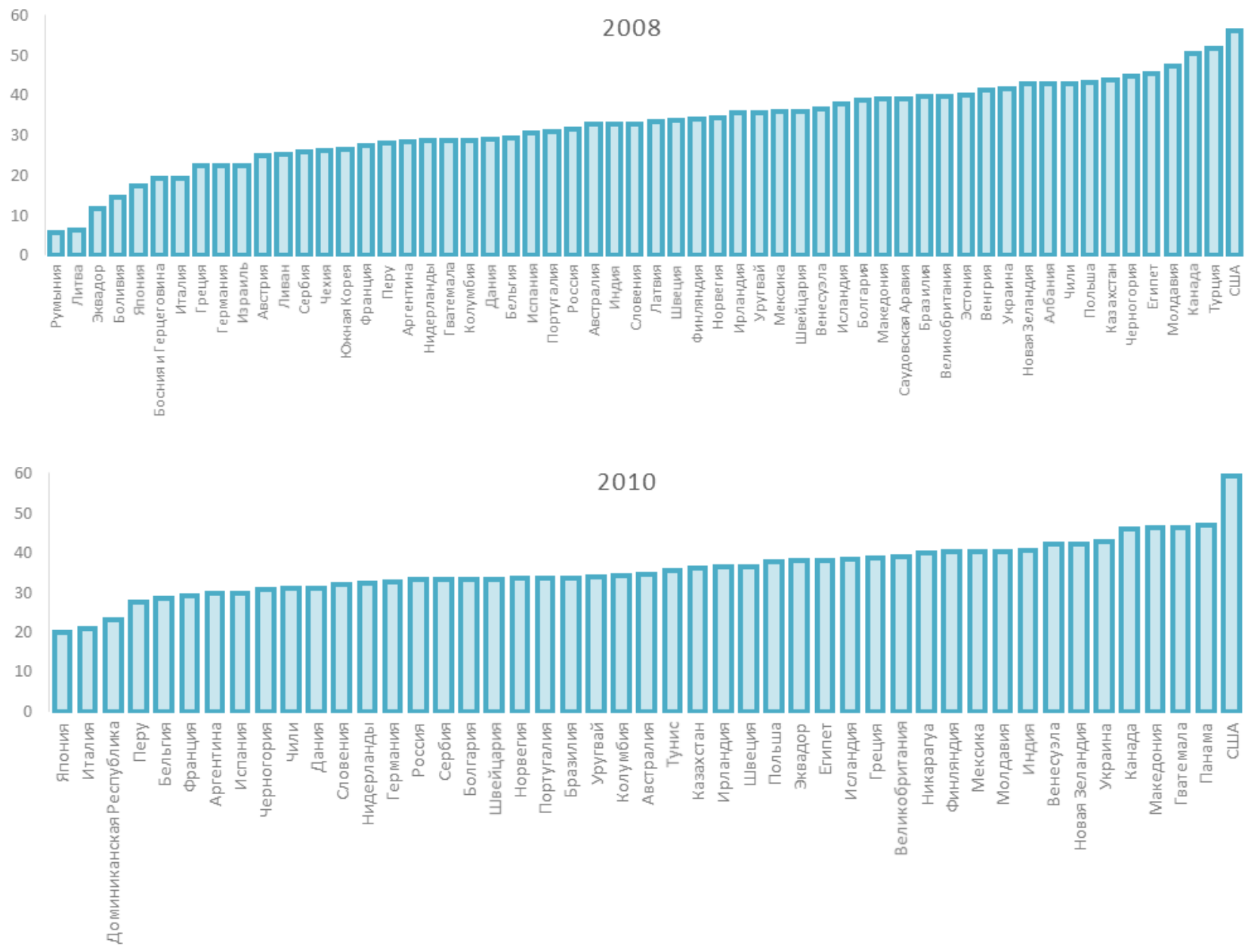

\section{Рисунок 5. Кумулятивный процент родов на пункцию после ЭКО/ИКСИ}

Источник: [Dyer et al. 2016].

Двойни и тройни в мире в целом после ВРТ рождались чаще, чем в Европе как отдельном регионе: соответственно 21,8 и 1,3\% всех рождений в мире после ВРТ в 2008 г., 20,5 и 1,0\% в 2009 г. и 20,4 и 1,1\% в 2010 г. Естественно, меньше всего многоплодия было в регионах, где в среднем подсаживали меньше эмбрионов (в Австралии/Новой Зеландии $8,2 \%$ двоен в 2010 г.), а больше всего там, где упорно продолжали подсаживать три эмбриона (30,0\% двоен на Ближнем Востоке в 2010 г.). Тройни получались лишь в 0,1\% случаев в Австралии/Новой Зеландии в 2010 г. и в 3,8\% случаев в Латинской Америке в 2008 г.

Донация ооцитов на мировом уровне за эти годы выросла на $35,8 \%$, существенная часть роста произошла за счет специализировавшейся на этой технике Испании (48,7\% всех донорских циклов в Европе и 19,4\% - в мире) и США, «ответственных» за 33,3\% мировых переносов эмбрионов от донорской яйцеклетки. По этнокультурным причинам донация ооцитов недоступна в Японии, большей части стран Ближнего Востока и основных немецко-говорящих странах Европы - Германии, Австрии и Швейцарии (что опять-таки, как минимум в некоторых случаях и в некоторых из этих регионов и стран, становится причиной для репродуктивного лечения за границей). 
Всего эта техника обеспечила в мире за эти три года появление 66769 детей, в более чем 60\% случаев реципиентами донорских клеток выступали женщины старше 40 лет.

За этот же период 8593 ребенка родились после преимплантационной диагностики. Это быстро развивающаяся область репродуктивной медицины, способная существенно помочь женщинам и парам с носительством наследственных заболеваний, старшего репродуктивного возраста, а также уже имеющим «за плечами» опыт нескольких неудачных ЭКО, в которых не было имплантации.

Доступность ВРТ соответствует целям развития тысячелетия в области репродуктивного здоровья (Цель развития тысячелетия 5В, Цель устойчивого развития 3.7). Данные по распространенности и эффективности ВРТ важны для разработки политики, клинической практики, образования и адвокации.

Ближний Восток и Латинская Америка отличаются повышенным использованием техники ИКСИ: например, почти 100\% на Ближнем Востоке. Причины этого до конца неясны, но могут быть связаны с культурно обусловленной в этих регионах повышенной важностью биологического отцовства. В среднем по миру ИКСИ используется примерно в $65 \%$ случаев ЭКО/ИКСИ (как дополнительная техника), интересно, что в Азии - только в $55 \%$ случаев, а в Европе цифры в целом совпадают с общемировыми средними.

В тех случаях, когда пациенты оплачивают ВРТ самостоятельно, они более склонны к тому, чтобы подсаживать несколько эмбрионов за один раз, даже если им говорят о связанных с многоплодием рисках, в надежде на большую эффективность каждого переноса, а также и с учетом того, что 2 ребенка до сих пор для многих - это идеальное число детей, и возможность родить обоих за одну беременность не для одной женщины изначально представляется скорее бонусом, чем трагедией. Однако в случаях, когда все оплачивает государство, закон или медицинская корпорация репродуктологов имеет приоритетное право голоса при решении вопроса о том, сколько эмбрионов подсаживать за один раз, и их среднее число уменьшается [Hamilton, McManus 2012; Chambers 2014].

\section{ИСПОЛЬЗОВАНИЕ ВРТ в РОССИИ}

ВРТ в России изучаются уже длительное время, в частности в области демографии надо отметить работы Н. Русановой [Русанова 2009; Русанова, Гордеева 2016], по истории ЭКО в нашей стране интересна книга [Никитин, Аншина 2011]. По России в настоящее время (декабрь 2016 г.) уже доступны данные за 2014 г. Это 20-й отчет РАРЧ - Российской ассоциации репродукции человека. В этом году в общей сложности было выполнено ${ }^{11}$ 95628 циклов ВРТ, и кроме этого 13971 инсеминация (данные об инсеминациях собираются в России с 2005 г., процент наступления беременностей в них составляет от 8 до 15). Участвовали 133 клиники (79,6\% от общего числа репродуктивных клиник России). Всего произошло 18809 родов в циклах ЭКО-ИКСИ (21,2\% к выполненным циклам), 1841 роды в 6927 циклах с использованием донорских ооцитов $(26,6 \%)$. В «свежих» циклах

${ }^{11}$ Источник всех статистических показателей данного раздела [РАРЧ 2015]. 
донорская сперма использовалась в 4238 случаях (4,8\%), хирургическое извлечение сперматозоидов происходило в 994 случаях $(1,1 \%)$, дозревание эмбрионов в «пробирке» (метод, который в России применяют чаще, чем в других странах) было выполнено в 314 случаях (62 или 19,7\% из них завершились родами), донорство эмбрионов произошло 914 раз, из них 293 (32,1\%) завершились родами. Пациенток в возрасте старше 40 лет было примерно 14\%, редукция эмбрионов была выполнена 54 раза. ЭКО-ИКСИ с преимплантационной диагностикой было выполнено 1266 раз (358 родов или 28,3\%), суррогатное материнство использовалось 1318 раз (388 родов или 29,4\%), инсеминация спермой мужа - 10178 раз (107 или 10,9\% родов), спермой донора - 3793 раза (597 или $15,7 \%$ родов).

По данным Росстата, среднее население России в 2014 г. составляло 143,8 млн. человек, соответственно, количество циклов на 1 млн населения составляло 665. Это не очень высокий показатель, он означает, что доступность далека от предельной. Видимо, существенны финансовые барьеры (это вероятно, так как не все могут получить достаточное количество государственных квот), либо транспортные (наиболее вероятны в России при огромной площади страны, частые путешествия даже в областной город доступны не всем, при этом в 2014 г. 33,1\% клиник были расположены в Москве и СанктПетербурге, их доля в количестве проводимых лечебных циклов была еще большей 45,9\%). Возможно также, что в России сильны предрассудки в отношении использования ВРТ, позиция Православной церкви по отношению к ЭКО и другим технологиям недружественна $^{12}$. Могут существовать и предубеждения, исходящие из «неестественности» процесса, поскольку «натуралистическое» отношение к родам и уходу за детьми довольно распространено. Соответственно многие бесплодные женщины и мужчины могут оказываться от ВРТ, поскольку не хотят «идти против Бога и природы».

Как бы то ни было, эффективность ВРТ в России соответствует мировому уровню. Частота наступления беременностей практически не менялась 5 лет с 2009 по 2014 г. и составляла чуть более 30\% в программах ЭКО, 27-29\% в программах ИКСИ, в программах донорства ооцитов она была выше - около 38\%, а в криоциклах она выросла к 2014 г. до примерно 37\%, так как улучшились техники замораживания эмбрионов. Доля родов после ВРТ в общей рождаемости страны в 2014 г. составила 1,03\%, впервые превысив 1\%. Процент ВРТ-детей еще выше $(1,27 \%)$, так как многоплодие при использовании этих технологий выше, чем в среднем по популяции (22,2\% после ВРТ в России). Всего за 20 лет сбора статистических данных в России родилось как минимум 130797 ВРТ-детей, причем надо учитывать, что это неполные данные, так как не все клиники их предоставляли все это время, а также и пациенты сообщали врачам не обо всех исходах беременности.

12 См., например, «ЭКО: дискуссия продолжается? Как Православная церковь относится к ЭКО?» (2010). Редакция портала «Православие и Мир». 21.06.2010. URL: http://www.pravmir.ru/eko-pora-menyat-

vzglyad-cerkvieko-diskussiya-prodolzhaetsya/ (дата обращения: 02.02.2017). Также в 2016 г. патриарх подписал обращение о запрете абортов, ЭКО и суррогатного материнства: URL: http://www.patriarchia.ru/db/text/4625720.html (дата обращения: 02.02.2017). 
Среднее число переносимых эмбрионов в России в 2014 г., по расчетам автора, составляло 1,8, что вполне соответствует европейским стандартам. Графики на рисунках 6 и 7 позволяют проанализировать соотношение эффективности (процент наступления беременностей и родов) при разном количестве переносимых эмбрионов и разной частоте наступления многоплодия, чреватого рисками плохого здоровья детей. Можно видеть, что, с одной стороны, многоплодие иногда возникает и при переносе одного эмбриона, поскольку он может, как и при естественной беременности, разделиться на два и более.

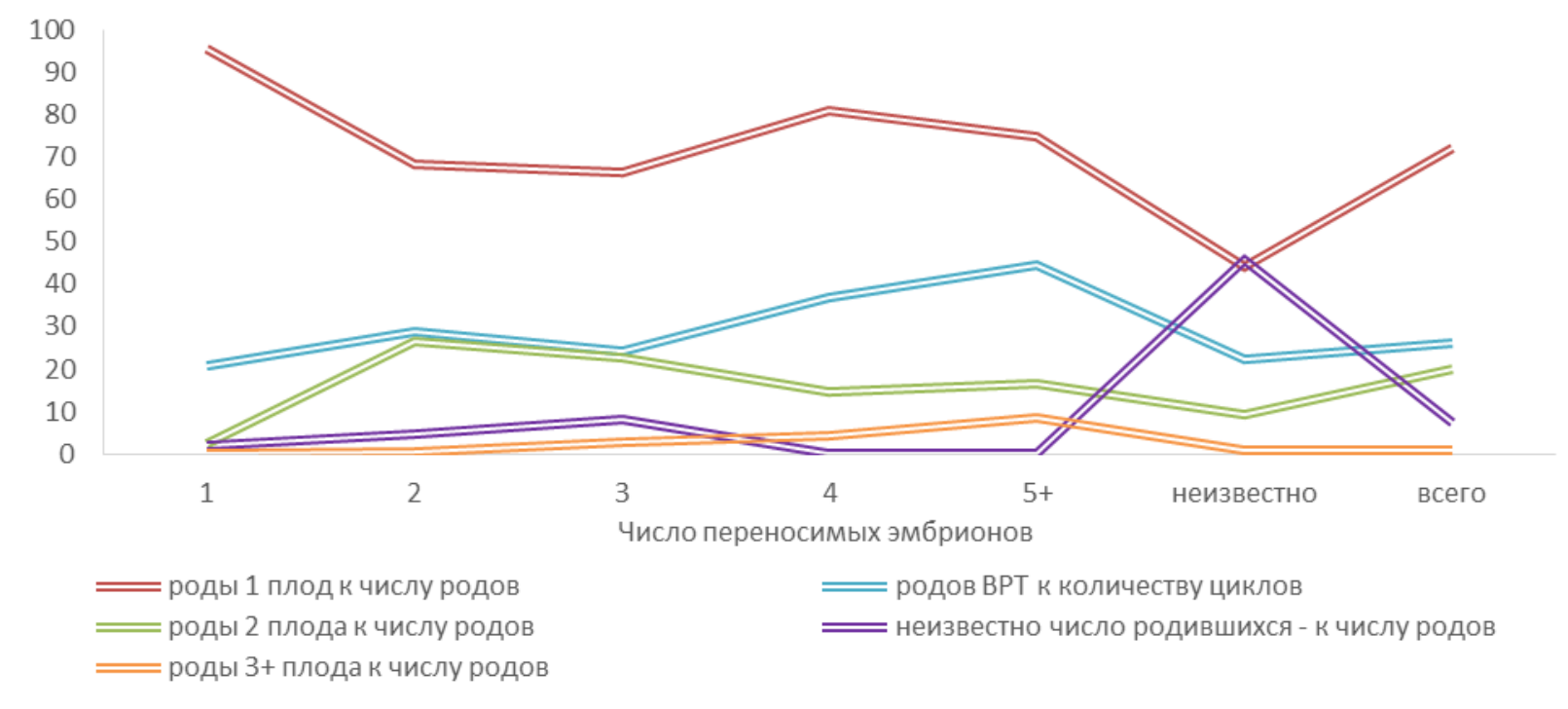

Рисунок 6. Отношение числа родов ВРТ к количеству циклов и доля родов с различным числом плодов в общем числе родов в зависимости от числа переносимых эмбрионов, Россия, 2014, \%

Источник: Расчеты автора по данным [РАРЧ 2015].

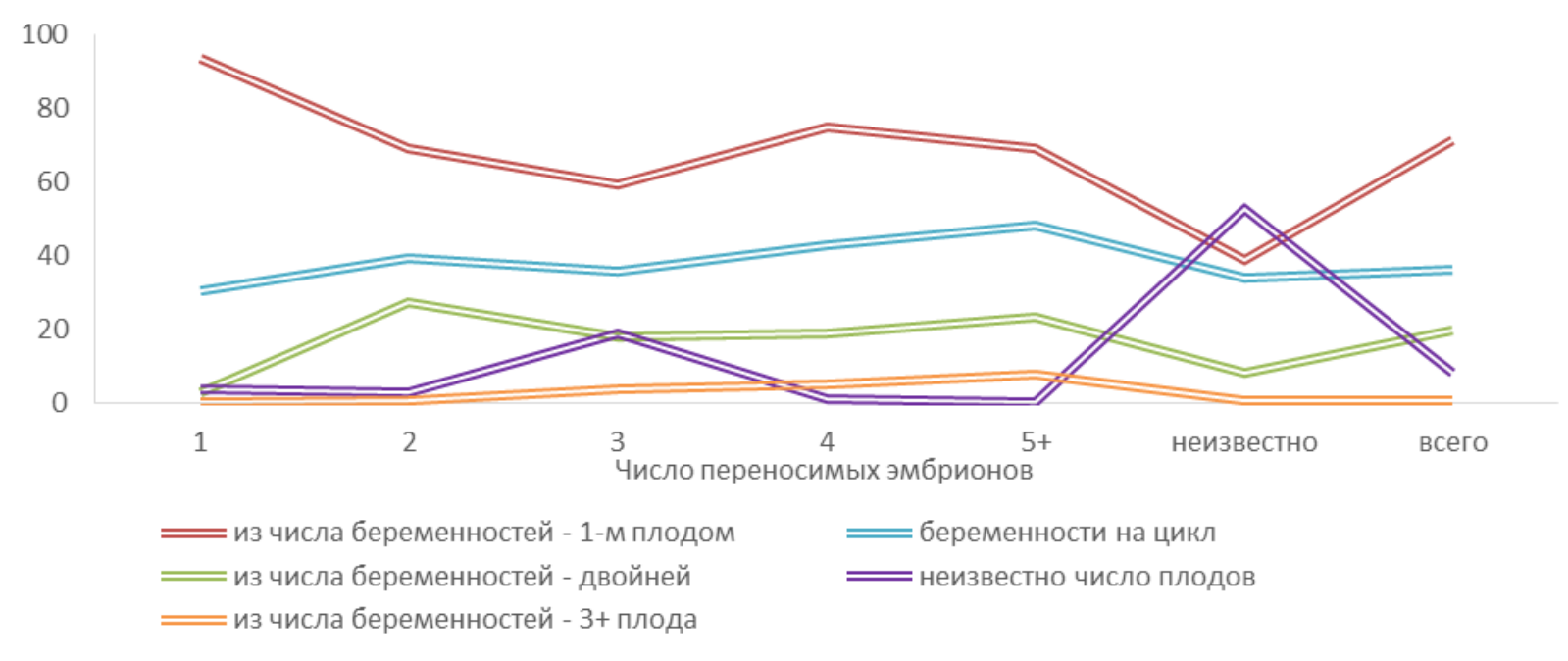

Рисунок 7. Отношение числа беременностей к количеству циклов и доля беременностей с разным числом плодов в общем числе беременностей в зависимости от числа переносимых эмбрионов, Россия, 2014, \%

Источник: Расчеты автора по данным [РАРЧ 2015]. 
С другой стороны, при переносе большего числа эмбрионов растет процент наступления беременностей и родов, т.е. эффективность. Но, конечно, увеличивается и многоплодие, что связано с рисками плохого здоровья детей. Эти риски на мировом уровне признаны важным основанием для того, чтобы бороться с многоплодием при применении ВРТ, в России с ним также стараются бороться. В связи с этой борьбой при современном уровне развития медицины рост эффективности технологий (в соответствии с приведенным выше определением) затормозился именно в ведущих, наиболее развитых странах, к которым в области репродуктивных технологий можно отнести и Россию (в том смысле, что у нас методики преодоления бесплодия вполне современны и эффективны, проблемы существуют лишь с их доступностью и соответствием уровню развития смежных областей медицины).

\section{ЗАКЛЮЧЕНИЕ}

Итак, ВРТ продолжают распространяться по миру и охватывать новые регионы и страны [Dyer et al. 2016]. В этом отношении за ними сохраняется значительный потенциал с точки зрения увеличения числа появляющихся таким образом на свет людей и вклада в рождаемость.

В то же время, с точки зрения эффективности в отношении преодоления бесплодия (скорее, вынужденной бездетности, так как к ним обращаются не только люди, страдающие определенными точно диагностированными репродуктивными заболеваниями, но и те, кто откладывал рождения до старшего репродуктивного возраста, а также, например, излечившиеся онкологические больные, люди нетрадиционной сексуальной ориентации и т.д., так что оценивать их потенциал только с точки зрения распространения собственно бесплодия в населении не совсем верно) многие показатели - насколько позволяет судить статистика, собираемая в разных странах по различным правилам, неполная и не всегда хорошего качества - вышли на некое «плато», рост приостановился, произошла стабилизация. В некоторых странах показатели доступности этих технологий населению также стабилизировались (в основном в тех, где они приблизились к максимальным, там же и процент ВРТ-детей в рождаемости страны наиболее высок и не очень меняется год от года, хотя все-таки немного растет: сейчас максимальная цифра - 5,8\% в Дании, еще недавно максимум составлял чуть более 4\% [Kupka et al. 2016]).

Стабилизация может быть связана с тем, что «старые» репродуктивные технологии - ЭКО, ИКСИ, суррогатное материнство и донорство гамет - уже заняли в области репродуктивных опций свою «нишу». Потенциал ее увеличения невелик, хотя, несомненно, возможны новые прорывы в области медицинской науки, например, связанные с развитием преимплантационной диагностики (ПГД), которые могут значительно его увеличить. Также, несомненно, процент наступления беременностей падает в связи с борьбой с многоплодием, но зато рождающиеся ВРТ-дети имеют, в среднем, лучшее здоровье по сравнению, например, с 1990-ми годами, поскольку основные нарушения здоровья были связаны именно с многоплодием и - в связи с этим - с ранним рождением значительной части детей [Kupka et al. 2016]. 
Увеличение демографического значения ВРТ может произойти также, если: они станут доступны экономически большему числу людей; к ним будут чаще прибегать женщины относительно молодого репродуктивного возраста (до 34 или хотя бы до 40 лет); будет снижаться роль предрассудков и религиозных запретов (пока, однако, в ряде стран, напротив, происходит консервативный поворот и обсуждаются, в том числе и в России, различные запреты в области ЭКО); получат развитие новые технологии, например, позволяющие женщинам старшего возраста с помощью ЭКО иметь генетически своих детей (замораживание яйцеклеток и ткани яичника; донорство цитоплазмы, позволяющей матери сохранить с ребенком существенную часть генетической связи).

Все это будет вызывать новые биоэтические столкновения и потребует выработки определенных законодательных рекомендаций. При выработке таких рекомендаций должны учитываться не только постулаты религиозных и других этических систем, но и соображения прав человека на зачатие ребенка, в этом хочется согласиться с настаивающими на такой позиции авторами [Inhorn 2009; Zegers-Hochschild et al. 2013]. B любом случае, остановить процессы развития науки, скорее всего, невозможно, и вряд ли нужно. Необходимо лишь стараться на каждом шагу осмыслять социальные последствия такого развития и принимать социально ответственные решения.

\section{ЛИТЕРАТУРА}

Исупова О.Г., А.В. Белянин, А.А. Гусарева (2014). ВРТ-современность в помощь традициям // Демоскоп Weekly. 615-616. URL: http://demoscope.ru/weekly/2014/0615/tema01.php (дата обращения: 12.04.2017).

Никитин А.И., М.Б. Аншина (2011). История ЭКО в России / Под ред. М.Б. Аншиной. М.: Медиа Сфера.

Петров Г.Н. (1959). Процесс оплодотворения вне организма яйцеклеток некоторых млекопитающих животных и человека: автореф. дис. на соискание ученой степени канд. мед. наук. Симферополь.

РАРЧ (2015). Российская ассоциация репродукции человека. Отчет за 2014 год // Проблемы репродукции. 21/6: 8-24.

Русанова Н.Е. (2009). Бездетная семья в России: политика государства и выбор супругов // Труд и социальные отношения. 8: 25-30.

Русанова Н.Е., В.Л. Гордеева (2016). Вспомогательные репродуктивные технологии: потребности и регулирование при низкой рождаемости // Народонаселение. 3(73): 3446.

Brezina P.R., Y. Zhao (2012). The ethical, legal, and social issues impacted by modern assisted reproductive technologies // Human reproduction. Article ID 686253. 7 p. URL: http://dx.doi.org/10.1155/2012/686253 (assessed: 15.12.2016).

Centers for Disease Control and Prevention, American Society for Reproductive Medicine, Society for Assisted Reproductive Technology (2014). Assisted reproductive technology fertility clinic success rates report in 2012. Atlanta, GA: US Department of health and human services. 
Chambers G.M., E.A. Sullivan, O. Ishihara, M.G. Chapman, G.D. Adamson (2009). The economic impact of assisted reproductive technology: a review of selected developed countries // Fertility and sterility. 91/6: 2281-2294.

Chambers G.M., V.P. Hoang, E.A. Sullivan, M.G. Chapman, O. Ishihara, F. Zegers-Hochschild, K.G. Nygren, G.D. Adamson (2014). The impact of consumer affordability on access to assisted reproductive technologies and embryo transfer practices: an international analysis // Fertility and sterility. 101: 191-198.

Damelio J., K. Sorensen (2008). Enhancing autonomy in paid surrogacy // Bioethics. 22/5: 269277.

Dyer S., G.M. Chambers, J. de Mouzon, K.G. Nygren, F. Zegers-Hochschild, R. Mansour, O. Ishihara, M. Banker, G.D. Adamson (2016). International committee for monitoring assisted reproductive technologies world report: Assisted reproductive technologies 2008, 2009 and 2010 // Human reproduction. 31(7): 1588-609.

Ehrich K., C. Williams, B. Farsides, J. Sandall, R. Scott (2007). Choosing embryos: ethical complexity and relational autonomy in staff accounts of PGD // Sociology of health and illness. 29/7: 1091-1106.

Ethics Committee...(2009). Ethics Committee of the American society for reproductive medicine. Interests, obligations, and rights of the donor in gamete donation // Fertility and sterility. 91/1: 22-27.

Ferraretti A.P., G. Pennings G., L. Gianaroli, F. Natali, M.C. Magli (2010). Cross-border reproductive care: a phenomenon expressing the controversial aspects of reproductive technologies // Reproductive biomedicine. 20/2: 261-266.

Ferraretti A.P., V. Goossens, M. Kupka, S. Bhattacharya, J. de Mouzon, J.A. Castilla, K. Erb, V. Korsak, A.N. Andersen (2013). The European IVF-monitoring (EIM) consortium, for the European society of human reproduction and embryology (ESHRE), Assisted reproductive technology in Europe, 2009: results generated from European registers by ESHRE // Human reproduction. 28: 2318-2331.

Fortunato A., E. Tosti (2011). The impact of in vitro fertilization on health of the children: an update // European journal of obstetrics, gynecology and reproductive biology. 154/2: 125129.

Garcia J. (1998). Profiling assisted reproductive technology: the society for assisted reproductive technology registry and the rising costs of assisted reproductive technology // Fertility and sterility. 69/4: 624-626.

Hamilton B.H., B. McManus (2012). The effects of insurance mandates on choices and outcomes in infertility treatment markets // Health economics. 21: 994-1016.

Hanna J.K. (2010). Revisiting child-based objections to commercial surrogacy // Bioethics. 24/7: $341-347$.

Inhorn M.C. (2009). Right to assisted reproductive technology: overcoming infertility in lowresource countries // International journal of gynecology and obstetrics. 106: 172-174.

Jadva V., T. Freeman, W. Kramer, S. Golombok (2011). Sperm and oocyte donors experiences of anonymous donation and subsequent contact with their donor offspring // Human reproduction. 26/3: 638-645.

James S., R. Chilvers, D. Havemann, J.Y. Phelps (2010). Avoiding legal pitfalls in surrogacy arrangements // Reproductive biomedicine. 21/7: 862-867. 
Kamel R.M. (2013). Assisted reproductive technology after the birth of Louise Brown // Journal of reproduction and infertility. 14/3: 96-109.

Kupka M.S., T. D’Hooghe, A.P. Ferraretti, J. de Mouzon, K. Erb, J.A. Castilla, C. Calhaz-Jorge, Ch. de Geyter, V. Goossens (2016). Assisted reproductive technology in Europe, 2011: results generated from European registers by ESHRE, The European IVF-monitoring consortium (EIM) for the European Society of human reproduction and embryology (ESHRE) // Human reproduction. 31/2: 233-248.

Ledger W.L., D. Anumba, M. Marlow, C.M. Thomas, E.C. Wilson (2006). The costs to the NHS of multiple births after IVF treatment in the UK // Journal of obstetrics and gynecology. 113/1: 21-25.

Levens E.D., A.H. DeCherney (2008). Human oocyte research: the ethics of donation and donor protection // Journal of the American medical association. 300/18: 2174-2176.

Levine A.D. (2011). The oversight and practice of oocyte donation in the United States, United Kingdom and Canada // HEC Forum. 23/1: 15-30.

Macaldowie A., E. Lee, G.M. Chambers (2015). Assisted reproduction technology in Australia and New Zealand 2013 // Assisted reproduction technology series no. 18. Sydney: The University of New South Wales.

Meirow D. (2008). Fertility preservation in cancer patients using stored ovarian tissue: clinical aspects // Current opinion in endocrinology, diabetes and obesity. 15/6: 536-547.

Murphy T.F. (2009). Ethics and the prohibition of donor gametes in fertility medicine // Reproductive biomedicine. 18/supplement 1: 60-67.

Omurtag K.R., A.K. Styer, D. Session, T.L. Toth (2009). Economic implications of insurance coverage for in vitro fertilization in the United States: a review // The journal of reproductive medicine. 54/11-12: 661-668.

Osberg B. (2006). For your first born child: an ethical defense of the exploitation argument against commercial surrogacy // Pennsylvania bioethics journal. 2/2: 42-45.

Paul M.S., R.E. Berger, R. Blyth, L. Frith (2010). Relinquishing frozen embryos for conception by infertile couples // Families, systems and health. 28/3: 258-273.

Rao G.D., R.C. Chian, W.S. Son, et al. (2004). Fertility preservation in women undergoing cancer treatment // The lancet. 363/9423: 1829-1830.

Riggs D.W., L. Russell (2011). Characteristics of men willing to act as sperm donors in the context of identity-release legislation // Human reproduction. 26/1: 266-272.

Sauer J.L. (2009). Competing interests and gamete donation: the case for anonymity // Seton Hall law review. 39/3: 919-954.

Sharp R.R., M.L. McGowan, J.A. Verma, et al. (2010). Moral attitudes and beliefs among couples pursuing PGD for sex selection // Reproductive biomedicine. 21/7: 838-847.

Spandorfer S.D., K. Bendikson, K. Dragisic, G. Schattman, O.K. Davis, Z. Rosenwaks (2007). Outcome of in vitro fertilization in women 45 years and older who use autologous oocytes // Fertility and sterility. 87/1: 74-76.

Van Rooij I.A., L.F. Bancsi, F.J. Broekmans, C.W. Looman, J.D. Habbema, E.R. Te Velde (2003). Women older than 40 years of age and those with elevated follicle-stimulating hormone levels differ in poor response rate and embryo quality in in vitro fertilization // Fertility and sterility. 79/3: 482-488. 
Zegers-Hochschild F., B.M. Dickens, S. Dughman-Manzur (2013). Human rights to in vitro fertilization // International journal of gynecology and obstetrics. 123: 86-89. 


\title{
ASSISTED REPRODUCTIVE TECHNOLOGIES: NEW OPPORTUNITIES
}

\author{
OLGA ISUPOVA
}

\begin{abstract}
The article attempts to evaluate the potential of assisted reproductive technologies to influence fertility, based on calculations made using the latest available statistical data from the world, Europe and Russia. It examines assisted reproductive technologies in a historical and ethical context, since both influence the readiness of different populations to use them to overcome involuntary childlessness and problems with reproductive health. The analysis, based on existing statistics (which have important quality limitations varying from one country to another and are probably incomplete), allows us to tentatively presuppose that, on a worldwide scale, many indicators of ART efficiency have reached a kind of "plateau" - that is, have stopped increasing and stabilized. In some countries, indicators of the availability of these technologies to the population have stabilized as well. This has happened in those countries where they are close to the maximum, where the share of ART children in the country's total annual fertility is over 4\%. The "old" reproductive technologies - in-vitro fertilisation, ICSI, surrogacy and gamete donation - have already occupied their "niche" in the area of reproductive options, and their growth potential now seems limited. One reason for this is the practice of limiting the number of embryos during one transfer to two in order to decrease the number of fetuses in one pregnancy, which leads, on the one hand, to a somewhat lower ART pregnancy rate, but on the other, to improved health of the resulting children. The demographic potential of ART can be increased if the following occur: they become economically and geographically accessible to larger numbers of people; they are used more often by women of a relatively younger reproductive age (younger than 34 or at least 40 years); the role of superstitions and religious bans of various associated practices is diminished; and new technologies are developed which would allow women of older reproductive ages to have their own genetic children (freezing of eggs and ovarian tissue, cytoplasm donation, etc.).
\end{abstract}

Keywords: reproductive technologies, bioethics, fertility, demographic potential of ART, reproductive choice.

Olga G. Isupova (oisupova@hse.ru), NATIONAL RESEARCH UnivERSity Higher School of Economics, Russia.

THE RESULTS OF THE PROJECT "DEMOGRAPHIC DEVELOPMENT IN RUSSIA IN 2005-2015 IN THE CONTEXT OF LONG-TERM TRENDS", CARRIED OUT WITHIN THE FRAMEWORK OF THE BASIC RESEARCH PROGRAM AT THE NATIONAL RESEARCH UNIVERSITY HigHER SCHOOL OF ECONOMICS (HSE) IN 2016, ARE PRESENTED IN THIS PAPER.

DATE RECEIVED : NOVEMBER 2016.

\section{REFERENCES}

Brezina P.R., Y. Zhao (2012). The ethical, legal, and social issues impacted by modern assisted reproductive technologies // Human reproduction. Article ID 686253. 7 p. URL: http://dx.doi.org/10.1155/2012/686253 (assessed: 15.12.2016).

Centers for Disease Control and Prevention, American Society for Reproductive Medicine, Society for Assisted Reproductive Technology (2014). Assisted reproductive technology fertility clinic success rates report in 2012. Atlanta, GA: US Department of health and human services.

Chambers G.M., E.A. Sullivan, O. Ishihara, M.G. Chapman, G.D. Adamson (2009). The economic impact of assisted reproductive technology: a review of selected developed countries // Fertility and sterility. 91/6: 2281-2294.

Chambers G.M., V.P. Hoang, E.A. Sullivan, M.G. Chapman, O. Ishihara, F. Zegers-Hochschild, K.G. Nygren, G.D. Adamson (2014). The impact of consumer affordability on access to 
assisted reproductive technologies and embryo transfer practices: an international analysis // Fertility and sterility. 101: 191-198.

Damelio J., K. Sorensen (2008). Enhancing autonomy in paid surrogacy // Bioethics. 22/5: 269277.

Dyer S., G.M. Chambers, J. de Mouzon, K.G. Nygren, F. Zegers-Hochschild, R. Mansour, O. Ishihara, M. Banker, G.D. Adamson (2016). International committee for monitoring assisted reproductive technologies world report: Assisted reproductive technologies 2008, 2009 and 2010 // Human reproduction. 31(7): 1588-609.

Ehrich K., C. Williams, B. Farsides, J. Sandall, R. Scott (2007). Choosing embryos: ethical complexity and relational autonomy in staff accounts of PGD // Sociology of health and illness. 29/7: 1091-1106.

Ethics Committee...(2009). Ethics Committee of the American society for reproductive medicine. Interests, obligations, and rights of the donor in gamete donation // Fertility and sterility. 91/1: 22-27.

Ferraretti A.P., G. Pennings G., L. Gianaroli, F. Natali, M.C. Magli (2010). Cross-border reproductive care: a phenomenon expressing the controversial aspects of reproductive technologies // Reproductive biomedicine. 20/2: 261-266.

Ferraretti A.P., V. Goossens, M. Kupka, S. Bhattacharya, J. de Mouzon, J.A. Castilla, K. Erb, V. Korsak, A.N. Andersen (2013). The European IVF-monitoring (EIM) consortium, for the European society of human reproduction and embryology (ESHRE), Assisted reproductive technology in Europe, 2009: results generated from European registers by ESHRE // Human reproduction. 28: 2318-2331.

Fortunato A., E. Tosti (2011). The impact of in vitro fertilization on health of the children: an update // European journal of obstetrics, gynecology and reproductive biology. 154/2: 125129.

Garcia J. (1998). Profiling assisted reproductive technology: the society for assisted reproductive technology registry and the rising costs of assisted reproductive technology // Fertility and sterility. 69/4: 624-626.

Hamilton B.H., B. McManus (2012). The effects of insurance mandates on choices and outcomes in infertility treatment markets // Health economics. 21: 994-1016.

Hanna J.K. (2010). Revisiting child-based objections to commercial surrogacy // Bioethics. 24/7: 341-347.

Inhorn M.C. (2009). Right to assisted reproductive technology: overcoming infertility in lowresource countries // International journal of gynecology and obstetrics. 106: 172-174.

Isupova O.G., A.V. Belianin, A.A. Gusareva (2014). VRT-sovremennost' v pomoshch' traditsiyam [ART- modernity helping traditions] // Demoskop Weekly [Demoscope Weekly]. 615-616. URL: http://demoscope.ru/weekly/2014/0615/tema01.php (accessed: 12.04.2017).

Jadva V., T. Freeman, W. Kramer, S. Golombok (2011). Sperm and oocyte donors experiences of anonymous donation and subsequent contact with their donor offspring // Human reproduction. 26/3: 638-645.

James S., R. Chilvers, D. Havemann, J.Y. Phelps (2010). Avoiding legal pitfalls in surrogacy arrangements // Reproductive biomedicine. 21/7: 862-867.

Kamel R.M. (2013). Assisted reproductive technology after the birth of Louise Brown // Journal of reproduction and infertility. 14/3: 96-109. 
Kupka M.S., T. D’Hooghe, A.P. Ferraretti, J. de Mouzon, K. Erb, J.A. Castilla, C. Calhaz-Jorge, Ch. de Geyter, V. Goossens (2016). Assisted reproductive technology in Europe, 2011: results generated from European registers by ESHRE, The European IVF-monitoring consortium (EIM) for the European Society of human reproduction and embryology (ESHRE) // Human reproduction. 31/2: 233-248.

Ledger W.L., D. Anumba, M. Marlow, C.M. Thomas, E.C. Wilson (2006). The costs to the NHS of multiple births after IVF treatment in the UK // Journal of obstetrics and gynecology. 113/1: 21-25.

Levens E.D., A.H. DeCherney (2008). Human oocyte research: the ethics of donation and donor protection // Journal of the American medical association. 300/18: 2174-2176.

Levine A.D. (2011). The oversight and practice of oocyte donation in the United States, United Kingdom and Canada // HEC Forum. 23/1: 15-30.

Macaldowie A., E. Lee, G.M. Chambers (2015). Assisted reproduction technology in Australia and New Zealand 2013 // Assisted reproduction technology series no. 18. Sydney: The University of New South Wales.

Meirow D. (2008). Fertility preservation in cancer patients using stored ovarian tissue: clinical aspects // Current opinion in endocrinology, diabetes and obesity. 15/6: 536-547.

Murphy T.F. (2009). Ethics and the prohibition of donor gametes in fertility medicine // Reproductive biomedicine. 18/supplement 1: 60-67.

Nikitin A.I, M.B. Anshina (2011). Istoriya EKO v Rossii [History of IVF in Russia] / M.B. Anshina, ed. Moscow: Media Sphera.

Omurtag K.R., A.K. Styer, D. Session, T.L. Toth (2009). Economic implications of insurance coverage for in vitro fertilization in the United States: a review // The journal of reproductive medicine. 54/11-12: 661-668.

Osberg B. (2006). For your first born child: an ethical defense of the exploitation argument against commercial surrogacy // Pennsylvania bioethics journal. 2/2: 42-45.

Paul M.S., R.E. Berger, R. Blyth, L. Frith (2010). Relinquishing frozen embryos for conception by infertile couples // Families, systems and health. 28/3: 258-273.

Petrov G.N. (1959). Protsess oplodotvoreniya vne organizma yaytsekletok nekotorykh mlekopitayushchikh zhivotnykh i cheloveka: avtoref. dis. na soiskanie uchenoy stepeni kand. med. nauk [Process of out-of-the-body fertilization of oocytes of some mammals and humans: Candidate of medical science dissertation]. Simferopol.

RAHR (2015). Rossiyskaya assotsiatsiya reproduktsii cheloveka [Russian association for human reproduction]. Otchet za 2014 god [2014 Report] // Problemy reproduktsii [Problems of reproduction]. 21/6:8-24.

Rao G.D., R.C. Chian, W.S. Son, et al. (2004). Fertility preservation in women undergoing cancer treatment // The lancet. 363/9423: 1829-1830.

Riggs D.W., L. Russell (2011). Characteristics of men willing to act as sperm donors in the context of identity-release legislation // Human reproduction. 26/1: 266-272.

Rusanova N.E. (2009). Bezdetnaya sem'ya v Rossii: politika gosudarstva i vybor suprugov [Childless family in Russia: policy of the state and couple's choice] // Trud i sotsial'nye otnosheniya [Labor and social relations]. 8: 25-30.

Rusanova N.E., V.L. Gordeeva (2016). Vspomogatel'nye reproduktivnye tekhnologii: potrebnosti i regulirovanie pri nizkoy rozhdaemosti [Assisted reproductive technologies: 
needs and regulations in the condition of low fertility] // Narodonaselenie [Population]. 3(73):34-46.

Sauer J.L. (2009). Competing interests and gamete donation: the case for anonymity // Seton Hall law review. 39/3: 919-954.

Sharp R.R., M.L. McGowan, J.A. Verma, et al. (2010). Moral attitudes and beliefs among couples pursuing PGD for sex selection // Reproductive biomedicine. 21/7: 838-847.

Spandorfer S.D., K. Bendikson, K. Dragisic, G. Schattman, O.K. Davis, Z. Rosenwaks (2007). Outcome of in vitro fertilization in women 45 years and older who use autologous oocytes // Fertility and sterility. 87/1: 74-76.

Van Rooij I.A., L.F. Bancsi, F.J. Broekmans, C.W. Looman, J.D. Habbema, E.R. Te Velde (2003). Women older than 40 years of age and those with elevated follicle-stimulating hormone levels differ in poor response rate and embryo quality in in vitro fertilization // Fertility and sterility. 79/3: 482-488.

Zegers-Hochschild F., B.M. Dickens, S. Dughman-Manzur (2013). Human rights to in vitro fertilization // International journal of gynecology and obstetrics. 123: 86-89. 